\title{
A Novel Mouse Model of Subcortical Infarcts with Dementia
}

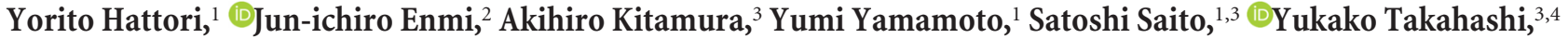 \\ Satoshi Iguchi, ${ }^{2}$ Masahiro Tsuji, ${ }^{1}$ Kenichi Yamahara, ${ }^{1}$ Kazuyuki Nagatsuka, ${ }^{4}$ Hidehiro Iida, ${ }^{2}$ and ${ }^{\circledR}$ Masafumi Ihara ${ }^{1,4}$ \\ ${ }^{1}$ Departments of Regenerative Medicine and ${ }^{2}$ Investigative Radiology, National Cerebral and Cardiovascular Center, Suita, Osaka 565-8565 Japan, \\ ${ }^{3}$ Department of Neurology, Kyoto University Graduate School of Medicine, Kyoto 606-8507 Japan, and ${ }^{4}$ Department of Stroke and Cerebrovascular \\ Diseases, National Cerebral and Cardiovascular Center, Osaka 565-8565 Japan
}

Subcortical white matter (WM) is a frequent target of ischemic injury and extensive WM lesions are important substrates of vascular cognitive impairment (VCI) in humans. However, ischemic stroke rodent models have been shown to mainly induce cerebral infarcts in the gray matter, while cerebral hypoperfusion models show only WM rarefaction without infarcts. The lack of animal models consistently replicating WM infarct damage may partially explain why many neuroprotective drugs for ischemic stroke or VCI have failed clinically, despite earlier success in preclinical experiments. Here, we report a novel animal model of WM infarct damage with cognitive impairment can be generated by surgical implantation of different devices to the right and left common carotid artery (CCA) in C57BL/6J mice. Implantation of an ameroid constrictor to the right CCA resulted in gradual occlusion of the vessel over $28 \mathrm{~d}$, whereas placement of a microcoil to the left CCA induced $\sim 50 \%$ arterial stenosis. Arterial spin labeling showed a gradual reduction of cerebral blood flow over $28 \mathrm{~d}$ post operation. Such reductions were more marked in the right, compared with the left, hemisphere and in subcortical, rather than the cortical, areas. Histopathological analysis showed multiple infarct damage in right subcortical regions, including the corpus callosum, internal capsule, hippocampal fimbria, and caudoputamen, in $81 \%$ of mice. Mice displaying such damage performed significantly poorer in locomotor and cognitive tests. The current mouse model replicates the phenotypes of human subcortical VCI, including multiple WM infarcts with motor and cognitive impairment.

Key words: cerebral infarction; model; mouse; stroke; vascular dementia; white matter

\section{Introduction}

Most lacunar infarctions develop in subcortical areas, including white matter (WM) regions such as the internal capsule (IC) and corona radiata. WM infarction damage results in deficits in motor function, one of the major determinants of poor prognosis after stroke. Several rodent models of ischemic stroke have been established, including those involving middle cerebral arterial occlusion, embolic stroke, and photothrombosis, which have been used in the development of novel neuroprotective agents (Durukan and Tatlisumak, 2007; Jiwa et al., 2010). Nevertheless, most clinical trials of agents have failed to produce any significant reduction in infarct volume in stroke patients (Richard Green et

Received Sept. 24, 2014; revised Jan. 20, 2015; accepted Jan. 28, 2015.

Author contributions: Y.H. and M.I. designed research; Y.H., J.-i.E., S.I., and M.I. performed research; Y.H., A.K., and M.I. contributed unpublished reagents/analytic tools; Y.H., J.-i.E., A.K., Y.Y., S.S., Y.T., S.I., M.T., K.Y., K.N., H.I., and M.I. analyzed data; Y.H., J.-i.E., and M.I. wrote the paper.

This work was supported by grants from the Ministry of Health, Labour and Welfare (No. 0605-1 to M.I.); the Ministry of Education, Culture, Sports, Science and Technology [Grant-in-Aid for Scientific Research (B), No. 23390233 to M.I.; Grant-in-Aid for Challenging Exploratory Research, No. 26640034 to Y.H.; Grant-in-Aid for Scientific Research (C), No. 25461867 to J.-i.E.]; and the Takeda Science Foundation (M.I.). We are indebted to Takako Kawada and Natsuki Hanada for their excellent technical assistance in staining and tissue sections and Dr. Ahmad Khundakar for editing this manuscript and providing many helpful suggestions. We thank Yosuke Kawai for assisting our work. We also acknowledge Hajime Fukuda, Yoshiko Hashikawa, and Masako Kunimi for supporting the magnetic resonance imaging experiments.

The authors declare no competing financial interests.

Correspondence should be addressed to Dr. Masafumi Ihara, Department of Stroke and Cerebrovascular Diseases, National Cerebral and Cardiovascular Center, Suita, 0saka 565-8565, Japan. E-mail: ihara@ncvc.go.jp.

DOI:10.1523/JNEUROSCI.3970-14.2015

Copyright $\odot 2015$ the authors $\quad 0270-6474 / 15 / 353915-14 \$ 15.00 / 0$ al., 2003; O'Collins et al., 2006). Most rodent models of ischemic stroke induce infarct damage in the cerebral cortex. Thus, the volume of cortical infarct damage has been used as a parameter in assessing potential novel neuroprotective compounds in such models (Gladstone et al., 2002). However, the beneficial effects of such agents on cortical gray matter have not always translated into clinical efficacy, presumably because the mechanism of ischemic WM damage differs from that found in gray matter. In addition, therapeutic efficacy in such models has tended to be judged solely on the basis of early histological outcomes, i.e., infarct volume, within the first few days. However, in clinical settings, behavioral outcomes at later time points are deemed preferable measures of therapeutic benefit.

Another determinant of poor prognosis after stroke is poststroke dementia. Multiple subcortical infarct damage is thought to be a major determinant of vascular cognitive impairment (VCI), the second most common cause of dementia after Alzheimer's disease. Approximately half of VCI cases are characterized by subcortical vascular brain injury, including WM infarcts (Pantoni and Garcia, 1995; Román et al., 2002; Ihara and Kalaria, 2014). Many rodent models have failed to replicate all characteristics of VCI (Hainsworth and Markus, 2008). For instance, rat hypoperfusion models have been generated by bilateral common carotid artery (CCA) occlusion (Wakita et al., 1994) or by placing ameroid constrictors (ACs) on the bilateral CCAs (Kitamura et al., 2012), while mouse hypoperfusion models have been generated by bilateral CCA stenosis (BCAS) using microcoils (Shibata 
et al., 2004). However, WM rarefaction in such models has been shown to be limited to the corpus callosum (CC), with no apparent WM infarct damage. This contrasts with human VCI, where ischemic stroke often develops in subcortical areas, such as the WM and striatum, which are supplied by end arteries (Fisher, 1968).

We therefore sought to develop a mouse model of subcortical WM infarct damage with cognitive impairment. As the BCAS model induces mild ischemia (hypoperfusion) with only WM rarefaction and implantation of ACs on the bilateral CCAs induces severe ischemia with acute infarctions and low survival rate (Hattori et al., 2014a), we applied a microcoil on the left CCA and an $\mathrm{AC}$ on the right CCA to expose mice to an intermediate ischemic insult. We hope that this animal model will herald important breakthroughs in the development of novel treatments for ischemic stroke and VCI.

\section{Materials and Methods}

Animals. Male C57BL/6J mice aged 10-12 weeks (weighing 24-29 g; Japan SLC) were used and given access to food and water ad libitum. All procedures were performed in accordance with the guidelines for animal experimentation from the ethical committee of the National Cerebral and Cardiovascular Center. All surgery was performed under anesthesia and all efforts were made to minimize suffering. We used moribund conditions as humane endpoints during the survival study. The moribund condition was defined as irreversible conditions leading inevitably to death. Signs of moribundity included (1) lack of responsiveness to manual stimulation, (2) immobility, and/or (3) an inability to eat or drink. In such conditions, animals were killed by carbon dioxide asphyxiation.

Study design. C57BL/6J male mice were assigned into five groups based on operative procedure: (1) asymmetric CCA surgery (ACAS) with an $\mathrm{AC}$ (inner diameter, $0.5 \mathrm{~mm}$; Tokyo Instruments) placed on the right CCA and a microcoil (inner diameter, $0.18 \mathrm{~mm}$; Samini) placed on the left CCA $(n=25$; Fig. $1 A)$, (2) BCAS operation (Shibata et al., 2004; $n=$ 7), (3) unilateral CCA stenosis (UCAS) with a microcoil placed only on the left CCA $(n=6)$, (4) unilateral CCA gradual occlusion (UCAgO) with an AC placed only on the right CCA $(n=6)$, and (5) sham operation $(n=15)$. Temporal changes of cerebral blood flow (CBF) were measured by laser speckle flowmetry (Omegazone; Omegawave) before and at 1, 3, 7,14 , and $28 \mathrm{~d}$ after ACAS, BCAS, UCAS, or UCAgO, and by arterial spin labeling (ASL; 7 tesla, BioSpec 70/30 USR; Bruker BioSpin) before and at 1, 7, 14, and $28 \mathrm{~d}$ after ACAS. Brain MRI (BioSpec 70/30 USR) was performed at 8, 15, 22, and $29 \mathrm{~d}$ after ACAS. Histologic evaluation of infarct changes was performed at 14 and $32 \mathrm{~d}$ after ACAS, UCAS, $\mathrm{UCAgO}$, or sham operation. Rotarod and wire hang tests were performed at $14 \mathrm{~d}$ after ACAS or sham operation; Y-maze test was performed at 14 and $28 \mathrm{~d}$ after ACAS, UCAS, UCAgO, or sham operation; and Morris water maze testing was performed at 28-32 d after ACAS, UCAS, UCAgO, or sham operation.

Ameroid constrictor. The AC consists of a titanium casing surrounding a hygroscopic casein material with an internal lumen. The casein component gradually absorbs water and consequently swells, leading to predictable narrowing and occlusion of the arterial lumen it encases. The inner diameter was $0.5 \mathrm{~mm}$, the outer diameter $3.25 \mathrm{~mm}$, and the length $1.28 \mathrm{~mm}$ (Kitamura et al., 2012).

Surgical implantation of microcoil and ameroid constrictor. The mice were anesthetized with $1.5 \%$ isoflurane. Through a midline cervical incision, both CCAs were exposed and freed from their sheaths. Two 4-0 silk sutures were placed around the distal and proximal parts of the left CCA. The artery was gently lifted by these sutures and placed between the loops of the microcoil just below the carotid bifurcation. The microcoil was implanted by rotation around the left CCA (Fig. 1A). An AC was implanted surgically on the right CCA (Fig. 1A). The BCAS operation procedure has been detailed previously (Shibata et al., 2004). Rectal temperature was maintained between 36.5 and $37.5^{\circ} \mathrm{C}$.

Blood pressure and pulse rate measurements. Blood pressure and pulse rate were noninvasively measured by the tail cuff method (Softron). The measurement sites were the roots of the tail of mice. The five recordings of blood pressure and pulse rate were averaged.

CBF measurement assessed with laser speckle flowmetry. Relative CBF was determined by laser speckle flowmetry, which obtains highresolution $2 \mathrm{D}$ imaging and has a linear relationship with absolute $\mathrm{CBF}$ values (Ayata et al., 2004). Recordings were performed through the skull under anesthesia with $1.5 \%$ isoflurane. The majority of periosteum, which adheres to the skull, was removed with fine-tip forceps. For each recording, the skull surface was wiped with saline-soaked gauze. Calibration was performed with a calibration reference device (Calibrator $\mathrm{S} / \mathrm{N}$ 080715-5; Omegawave) before each test. The mean CBF was measured in identically sized ROIs (900 pixels), located $1 \mathrm{~mm}$ posterior and $2 \mathrm{~mm}$ lateral from the bregma. These data reflect the CBF of the subsurface microvessels in the brain with a depth of $\sim 0.5 \mathrm{~mm}$ (Dong et al., 2011). CBF values were expressed as a percentage of the preoperative value.

MRI. All MRI scans were performed on a 7 tesla horizontal boreimaging system (BioSpec 70/30USR) equipped with a gradient system capable of a maximum gradient amplitude of $669 \mathrm{mT} / \mathrm{m}$ and a slew rate of $7989 \mathrm{~T} / \mathrm{m} / \mathrm{s}$. Radio-frequency transmission was performed using an 86 $\mathrm{mm}$ inner diameter volume coil. Signal was detected using a fourchannel, receive-only phased-array surface coil. The mice were anesthetized using isoflurane ( $4 \%$ for induction and $1.5-1.8 \%$ for maintenance) in $1.2 \mathrm{~L} / \mathrm{min}$ room air mixed with $0.1 \mathrm{~L} / \mathrm{min}$ oxygen. The animal was placed in a prone position, and the head fixed with a custom-designed head holder inside the magnet. Body temperature was monitored by rectal thermometer and maintained with a warm waterbed and warm air. Heart rate and respiratory rate were continuously monitored. $\mathrm{T}_{2}-$ weighted images were acquired using rapid acquisition with relaxation enhancement (RARE) sequence with the following parameters: RARE factor, 8; TR/TE, 2500/35.14 ms; number of averages, 2; matrix size, $200 \times 200$; FOV, $2.0 \times 2.0 \mathrm{~cm}^{2}$; in-plane spatial resolution, $100 \times 100$ $\mu \mathrm{m}^{2}$; slice thickness, $1.0 \mathrm{~mm}$, gapless; number of slices, 20 ; and scan time, 2 min $5 \mathrm{~s}$. Diffusion tensor images were acquired using spin-echo echo-planar imaging sequence with the following parameters: two shots; TR/TE, 10,000/28.38 ms; number of averages, 1 ; matrix size, $100 \times 100$; FOV, $2.0 \times 2.0 \mathrm{~cm}^{2}$; in-plane spatial resolution, $200 \times 200 \mu \mathrm{m}^{2}$; slice thickness, $1.0 \mathrm{~mm}$, gapless; number of slices, 20 ; b-value, $1000 \mathrm{~s} / \mathrm{mm}^{2}, 30$ directions; and scan time, $11 \mathrm{~min} 40 \mathrm{~s}$. In diffusion tensor images, generalized autocalibrating partially parallel acquisition technique was used with an acceleration factor of 2. Apparent diffusion coefficient (ADC) maps were calculated. 3D time-of-flight (TOF) MR angiography (MRA) images were acquired using a fast, low-angle shot sequence with the following parameters: TR/TE, 22.43/3.30 ms; number of averages, 1 ; matrix size, $200 \times 200 \times 200$; FOV, $2.0 \times 2.0 \times 2.0 \mathrm{~cm}^{3}$; spatial resolution, $100 \times 100 \times 100 \mathrm{\mu m}^{3}$; and scan time, $11 \mathrm{~min} 13 \mathrm{~s}$. In 3D TOF MRA, tilted, optimized nonsaturating excitation pulse and flow compensation were used. Maximum intensity projection images were reconstructed using AZEWIN (AZE).

CBF measurement of coronal slices was performed using a flowsensitive, alternating inversion recovery technique (Kim, 1995; Kim and Tsekos, 1997), an ASL-based method. In each of the nonselective and slice-selective experiments, 22 images with different inversion times were acquired using the RARE sequence with the following parameters: RARE factor, 72; TR/TE, 10,000/46 ms; number of averages, 1; matrix size, $128 \times 128$; FOV , $4.0 \times 4.0 \mathrm{~cm}^{2}$; in-plane spatial resolution, $313 \times 313$ $\mu \mathrm{m}^{2}$; slice thickness, $1.0 \mathrm{~mm}$; and number of slices, 1 . The following inversion time values were used: 30, 100, 200, 300, 400, 500, 600, 700, $800,900,1000,1100,1200,1300,1400,1500,1600,1700,1800,1950$, 2100 , and $2300 \mathrm{~ms}$. Total scan time was $8 \mathrm{~min} 24 \mathrm{~s}$. The CBF image was calculated from the obtained 44 images using ParaVison 5.1 (Bruker BioSpin). The CBF images of two coronal slices (bregma level and hippocampus level; bregma level $-2.0 \mathrm{~mm}$ ) were acquired. ROI analyses of CBF images were performed using the Dr. View/LINUX R2.5.0 program (Asahi Kasei Information System). In slice-selective inversion recovery images with an inversion time of $30 \mathrm{~ms}$ and the corresponding slices of the $\mathrm{T}_{2}$-weighted image, circular ROIs with a diameter of $1 \mathrm{~mm}$ were symmetrically placed on cerebral cortex region and subcortical region including $\mathrm{CC}$, caudoputamen $(\mathrm{CPu})$, and hippocampus, and superim- 
posed on CBF images. CBF values were expressed as a percentage of preoperative value.

Histologic evaluation of ischemic changes. The mice were deeply anesthetized with an intraperitoneal injection of sodium pentobarbital (40 $\mathrm{mg} / \mathrm{kg}$ ) and perfusion fixed transcardially with $0.01 \mathrm{~mol} / \mathrm{L}$ PBS, then $4 \%$ paraformaldehyde. Mouse brains were removed and divided coronally at the bregma, the bregma $-1 \mathrm{~mm}$, and bregma $-2 \mathrm{~mm}$ through the hippocampus. They were embedded in paraffin and sliced into $6-\mu \mathrm{m}$-thick coronal sections. Klüver-Barrera, and hematoxylin and eosin stains were used to observe any histological changes including infarct changes. The severity of the WM lesions was graded as normal (grade 0), disarrangement of the nerve fibers (grade 1), the formation of marked vacuoles (grade 2), and the disappearance of myelinated fibers (grade 3 ) as previously described (Wakita et al., 1995). For immunohistochemical detection, rabbit anti-GFAP antibody (a marker of astrocytes, 1:2000; DAKO), rabbit anti-Iba1 antibody (a marker of microglia, 1:200; Wako), rabbit anti-GST- $\pi$ antibody (a marker of oligodendrocyte, 1:100; Merck Millipore), mouse anti-neurofilament $\mathrm{H}$ nonphosphorylated (SMI32) antibody (a marker of damaged axons, 1:1000; Sternberger Monoclonals), and mouse anti- NeuN antibody (1:100; Merck Millipore) were used. Percentage area of GFAP-positive astrocytes, Ibal-positive microglia, GST- $\pi$-positive oligodendrocytes, and SMI32-positive axons in the CC were calculated using the ImageJ software package (National Institutes of Health).

In vivo imaging of CCA. After intravenous tail vein injection of fluorescein isothiocyanate-dextran $\left(2 \times 10^{6}\right.$ molecular weight, $200 \mu \mathrm{l}$ of 20 $\mathrm{mg} / \mathrm{ml}$; Sigma-Aldrich), the AC-implanted right CCA was visualized with a fluorescence microscope (MVX10; Olympus) at several time points after the operation.

Rotarod test. The rotarod test was performed at $14 \mathrm{~d}$ after ACAS or sham surgery by placing the mouse on a rotating drum (Muromachi Kikai) and measuring the time the mouse maintained its balance on the rod, as previously reported (Shibata et al., 2007). Rotarod speed was accelerated from 4 to $40 \mathrm{rpm}$ over a $5 \mathrm{~min}$ period. The test was repeated five times with an interval of 5 min between attempts.

Wire hang test. The wire hang test was performed at $14 \mathrm{~d}$ after ACAS or sham surgery, as previously reported (Shibata et al., 2007; Hattori et al., $2014 \mathrm{~b})$. A metallic wire $(2 \mathrm{~mm} \times 60 \mathrm{~cm})$ was secured to the top of a transparent, rectangular open-topped plastic box $(30 \mathrm{~cm}$ height $\times 60 \mathrm{~cm}$ width $\times 40 \mathrm{~cm}$ length). The wire was tightly fixed to the top of the tank to avoid vibration, which could interfere with the performance of the mouse. Mice were placed on the metallic wire and latency to fall was recorded. This was repeated five times with an interval of 5 min between attempts. Mean latency to fall was determined.

$Y$-maze test. Spatial working memory and spontaneous activity were assessed by the Y-maze test, as described earlier (Washida et al., 2010). The Y-maze test was conducted during the dark period $(7-11 \mathrm{pm})$ at 14 and $28 \mathrm{~d}$ after ACAS, and $28 \mathrm{~d}$ after UCAS, UCAgO, or sham surgery. The maze consists of three identical arms ( $40 \mathrm{~cm}$ long, $9.5 \mathrm{~cm}$ high, and $4 \mathrm{~cm}$ wide), labeled $\mathrm{A}, \mathrm{B}$, or $\mathrm{C}$, diverging at $120^{\circ}$ angles from a central point. The experiments were performed in a dimly illuminated room. After each mouse was tested, the floor of the maze was cleaned using super hypochlorous water-soaked paper for the elimination of smell to avoid olfactory cues. Each mouse was placed at the end of the start arm and allowed to move freely through the maze during an $8 \mathrm{~min}$ session without reinforcers such as food, water, or electric foot shock. The sequence of arm entries was manually recorded. A mouse was considered to have entered an arm when all four paws were positioned in the arm runway. An alternation was defined as entry into all three arms on consecutive occasions (e.g., the sequence, $\mathrm{ABCBCBCA}$ was counted as two alternations, with the first consecutive $\mathrm{ABC}$ and the last consecutive $\mathrm{BCA}$ out of six consecutive occasions; $33 \%$ alternations). The maximum alternation was calculated as the total number of arm entries minus two, and the percentage of alternation was calculated as (actual alternation/maximum alternation) $\times 100$. The total number of arms entered during the sessions, which reflects spontaneous activity, was also recorded. Mice that entered arms less than eight times during the test were eliminated because their data were not considered to reflect precise alternation.
Morris water maze test. The Morris water maze test was performed at 28-32 d after ACAS, UCAS, UCAgO, or sham surgery as previously reported (Hattori et al., 2014b). It consists of a circular pool (diameter, $120 \mathrm{~cm}$; depth, $40 \mathrm{~cm}$ ) and a set of video analysis systems (EthoVision XT5; Noldus). The pool was filled with water containing nontoxic white paint to a depth of $30 \mathrm{~cm}$. A clear, circular platform (diameter, $8 \mathrm{~cm}$ ) was submerged $1 \mathrm{~cm}$ below the water surface in the center of one quadrant of the pool (target quadrant). A red cross sign and blue upward arrow at the opposite side of the red cross sign were used as orientation cues for swimming. On the first $4 \mathrm{~d}$, we performed four trials per day with a $5 \mathrm{~min}$ interval between attempts (acquisition phase). The platform was kept in the same position during the acquisition phase. Mice were placed at the starting position (the quadrant adjacent to the target one; cf. Fig. $8 \mathrm{C}$, Zone 2) and released into the water. Each mouse was allowed to swim for $60 \mathrm{~s}$, discover the hidden platform, and climb onto it. The trial was immediately terminated after the mouse arrived on the platform or after $60 \mathrm{~s}$ had elapsed. When a mouse succeeded in climbing onto the platform, it was permitted to remain there for $10 \mathrm{~s}$. If a mouse did not reach the platform within $60 \mathrm{~s}$, it was placed there and allowed to remain for $15 \mathrm{~s}$. Latency to reach the platform (escape latency) and mean swimming speed were recorded. On the fifth day (the last day), the mice were subjected to the probe trial session in which the platform was removed from the pool and the mice were allowed to swim for $60 \mathrm{~s}$ to search for it. The duration of swimming in each quadrant was recorded.

Statistical analysis. Statistical analysis was conducted using StatView (SAS Institute). All values are expressed as means \pm SEM in the figures. Data were analyzed by unpaired $t$ test unless noted otherwise. Differences with $p<0.05$ were considered statistically significant in all analyses.

\section{Results}

\section{Gradual narrowing of right CCA subjected to AC}

Placement of the AC on the right CCA produced the expected narrowing of the inner lumen (Fig. $1 B$ ). The AC gradually narrowed up to $28 \mathrm{~d}$ post operation and finally occluded (Fig. $1 B$ ). In vivo vessel imaging with fluorescein isothiocyanate-dextran showed lack of fluorescence within the right CCA proximal to the $\mathrm{AC}$ at day 28 post implantation of AC, indicating that blood flow ceased proximal to AC (Fig. 1C).

\section{Mortality rates}

The mortality rate in the ACAS group was 20.0\% (5/25), while all mice survived until 28 d post operation in the BCAS, UCAS, $\mathrm{UCAgO}$, and sham surgery group. In the nonsurviving ACAS mice, the laser speckle flowmetry finally showed significant reductions of $\mathrm{CBF}<20-30 \%$ of the baseline level reflecting massive infarctions or hemodynamic derangements (data not shown).

\section{Mean blood pressure and pulse rate of surviving mice}

The mean blood pressure did not differ significantly among the three groups after $28 \mathrm{~d}$ following each operation (ACAS, $71.3 \pm$ $1.9 \mathrm{mmHg}$; BCAS, $71.5 \pm 1.8 \mathrm{mmHg}$; sham operation, $71.1 \pm 2.2$ $\mathrm{mmHg}$ ), and pulse rate was not significantly different among the three groups (ACAS, $656 \pm 25 \mathrm{bpm}$; BCAS, $679 \pm 20 \mathrm{bpm}$; sham operation, $681 \pm 27 \mathrm{bpm})$.

\section{Temporal profiles of cortical surface CBF recorded by laser speckle flowmetry}

At $1 \mathrm{~d}$ after BCAS operation, cortical surface CBF sharply dropped to $72.4 \%$ of the baseline level, and started to recover at $3 \mathrm{~d}$ and reached to $82.5 \%$ at $28 \mathrm{~d}$. In contrast, in the ACAS group, the acute phase observed in the BCAS group was abolished, and the $\mathrm{CBF}$ was significantly higher than the $\mathrm{CBF}$ of the BCAS group at $1 \mathrm{~d}$ (microcoil side, $83.7 \%$; AC side, $87.2 \%$ ) after operation. However, $\mathrm{CBF}$ in the ACAS group continued to decrease and was significantly lower than that of the BCAS group at $7 \mathrm{~d}$ after oper- 
A

$\mathrm{R}$

L

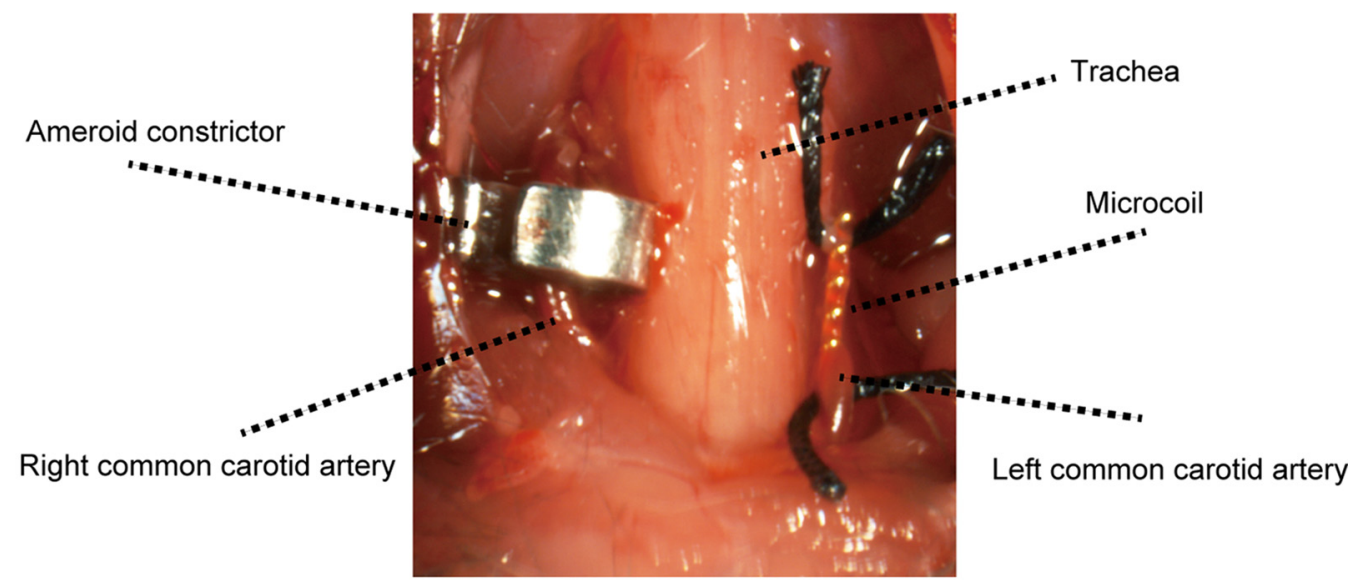

B

pre

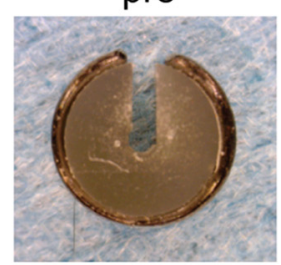

7 days

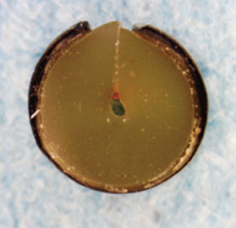

14 days

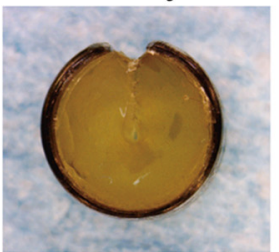

28 days

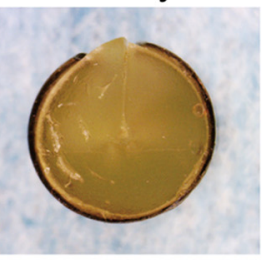

28 days

C
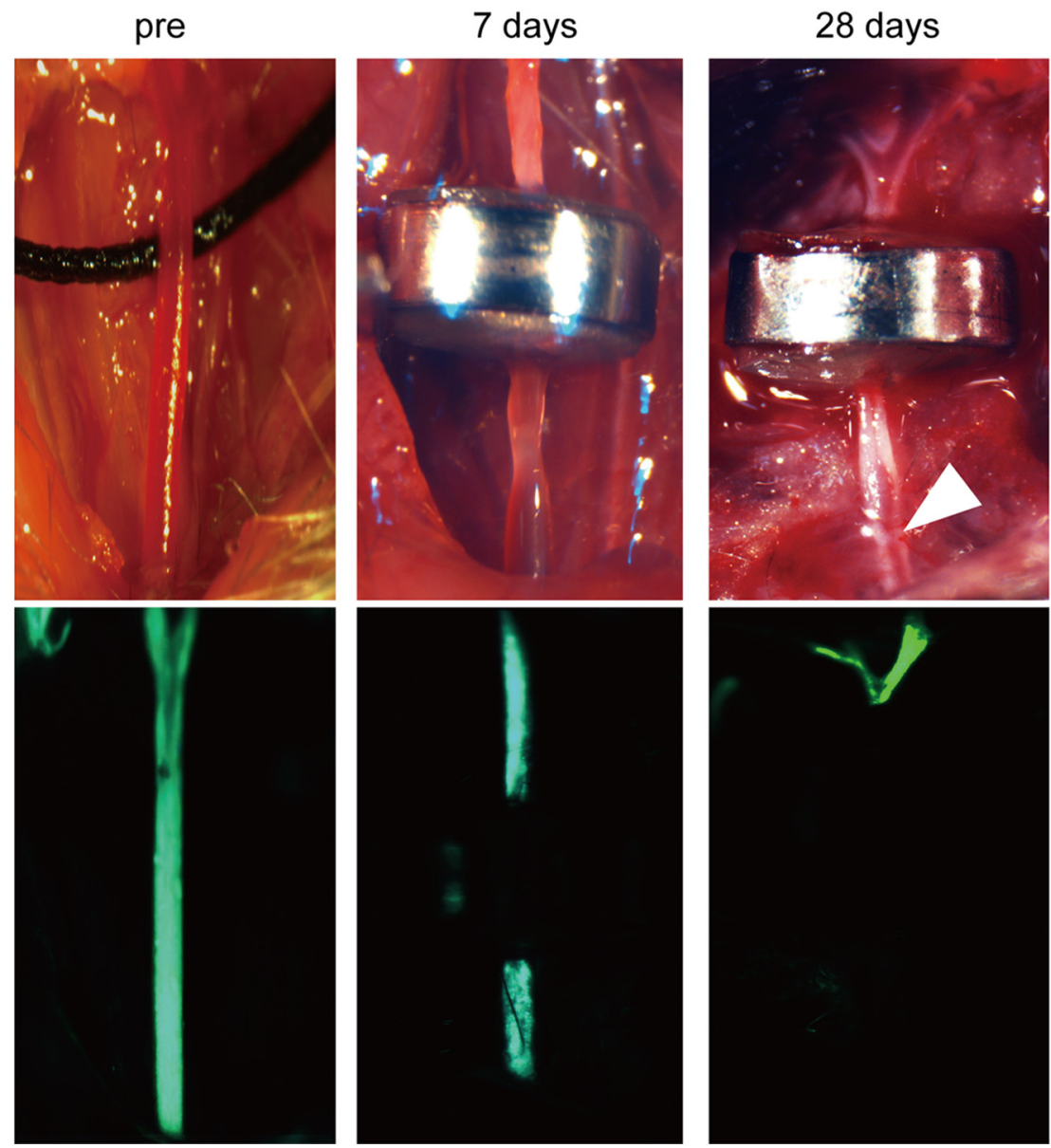

Figure 1. The AC gradually occluded the right CCA over $28 \mathrm{~d}$. $A$, An image showing surgical implantation of the $A C$ on the right $C C A$ and the microcoil on the left CCA. $B$, Representative images of ACs at indicated time points showing that a central hole (lumen) gradually narrows, with complete occlusion at $28 \mathrm{~d}$. C, Representative images of the right CCA with $A C$ at indicated time points (top) and their fluorescent images taken after tail vein injection of fluorescein isothiocyanate-dextran (bottom). At day 28 , blood flow proximal to the AC was lacking due to intra-arterial thrombus (white arrowhead). $R$, right; L, left. 
A

L

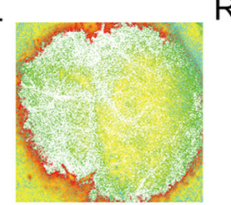

$\mathrm{L}$ : Microcoil side

R: AC side

$\mathrm{R}$
ACAS

pre 1 day

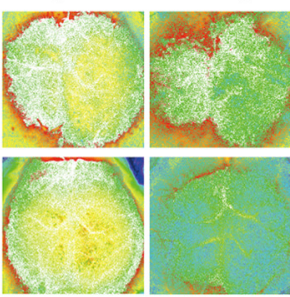

3 days

7 days

14 days

BCAS

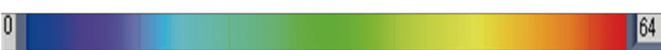

B

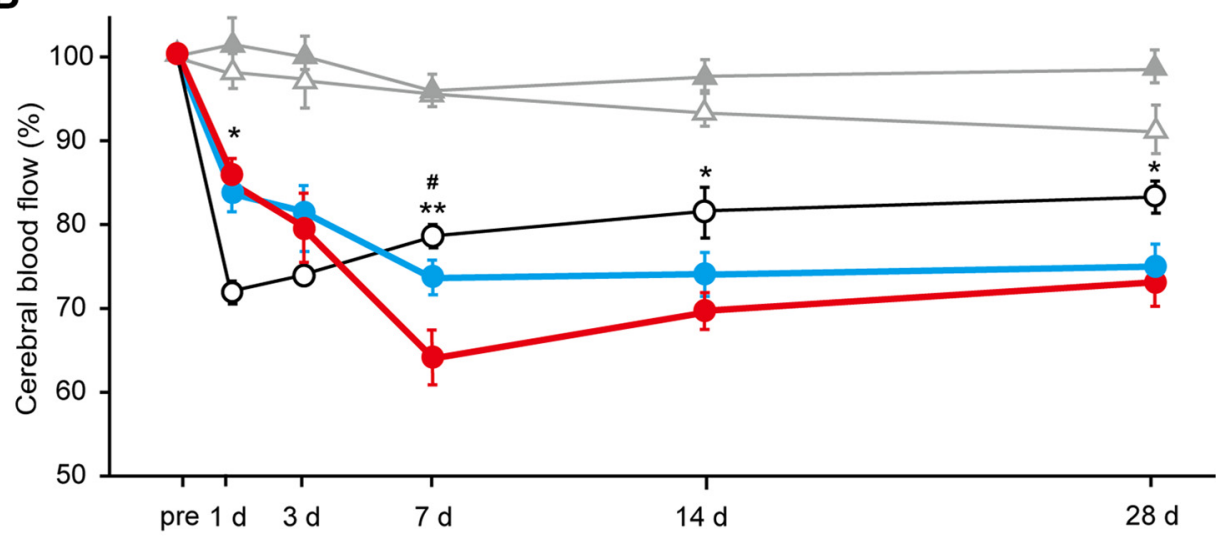

$\triangle U C A S \triangle U C A g O$ OBCAS Microcoil side (left hemisphere) $\mathrm{AC}$ side (right hemisphere)

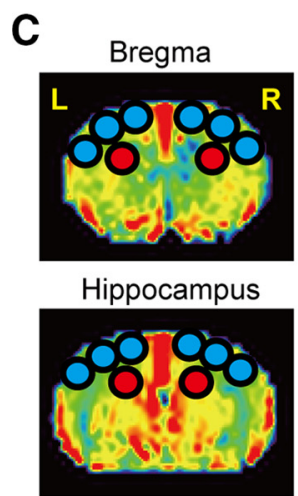

D

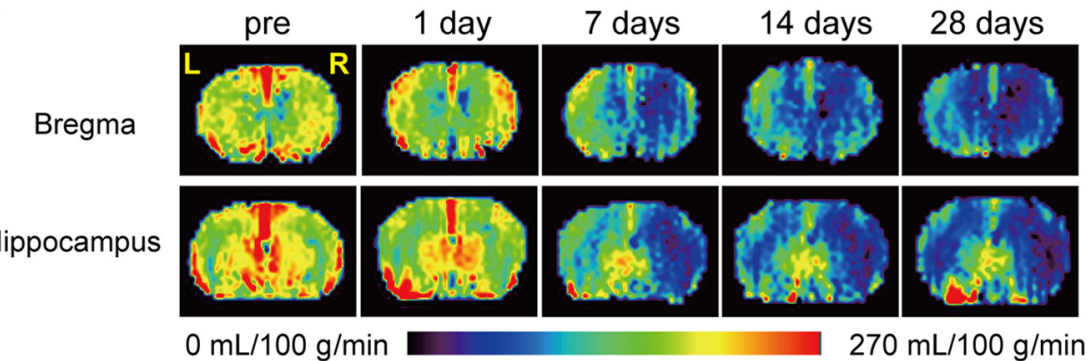

E

Bregma level

Hippocampus level
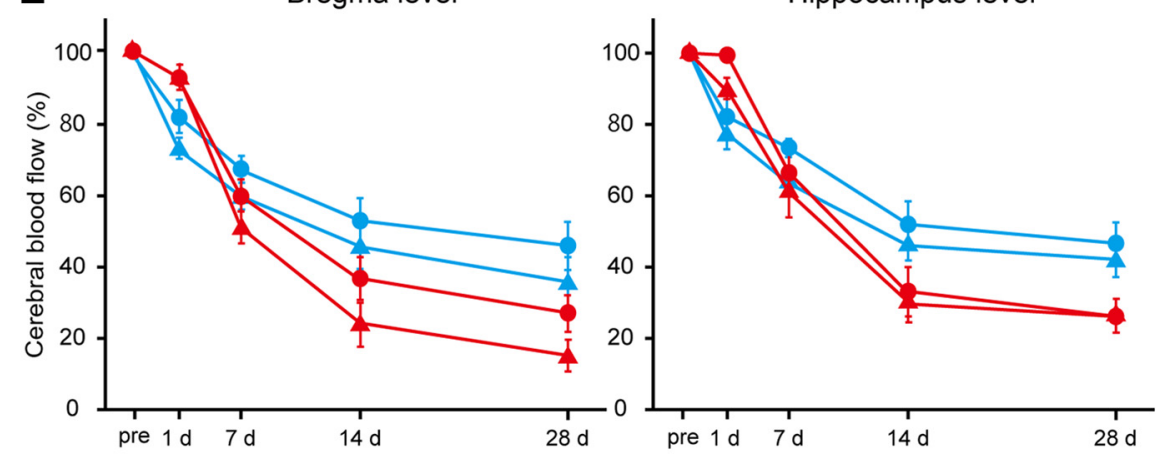

- Cortex (Microcoil side) A Subcortical area (Microcoil side)

- Cortex (AC side) $\Delta$ Subcortical area (AC side)

Figure 2. Temporal profiles of $C B F$ of surviving mice subjected to $A C A S$ or $B C A S . A, B$, Representative images of laser speckle flowmetry $(\boldsymbol{A})$ and temporal profiles of cortical surface $C B F(B)$ in mice subjected to ACAS $(n=16), \operatorname{BCAS}(n=7), \mathrm{UCAS}(n=6)$, and UCAgO $(n=6)$. The levels of cortical surface CBF estimates at indicated time points $(1,3,7,14$, and $28 \mathrm{~d}$ after operation) are shown as percentage of the baseline CBF. In ACAS mice, the CBF estimates are shown separately in the right (red, $A C$ side) and left hemisphere (blue, microcoil side). $C$, ROls used in the analyses of CBF images obtained from ASL magnetic resonance perfusion imaging. The CBF values in cerebral cortex region of each hemisphere were calculated from the three blue ROls, and red circles indicate ROI of subcortical area. $\boldsymbol{D}, \boldsymbol{E}$, Representative multislice coronal (BF images obtained from ASL at the bregma and hippocampal levels $(\boldsymbol{D})$ and temporal profiles of (BF in the cortex (circles) and subcortical area (triangles) of ACAS mice $(n=5 ; \boldsymbol{E})$. The levels of (BF are shown separately in the right (red, AC side) and left hemisphere (blue, microcoil side). ${ }^{*} p<0.01, A C A S$ versus BCAS; ${ }^{* *} p<0.05, A C A S$ versus $B C A S ; \# p<0.05$, microcoil side versus $A C$ side (in ACAS group). $R$, right; $L$, left. Error bars indicate mean \pm SEM. 
ation (microcoil side, $74.2 \%$; AC side, $64.3 \%)$. CBF at the microcoil side nearly plateaued thereafter until day 28, while $\mathrm{CBF}$ at the AC side slightly recovered after day 7 and approached the level at the microcoil side at day 28 (microcoil side, 75.3\%; AC side, 73.4\%). The levels of CBF of the ACAS group on days 14 and 28 were significantly lower than those of the BCAS group. A significant right-to-left difference in the CBF level was observed only at day 7 of the ACAS group (Fig. $2 A, B$ ). Mice with UCAS showed no change in CBF but mice with UCAgO showed gradual reduction of CBF up to $91.0 \%$ of the baseline level at day 28 after surgery (Fig. $2 B)$.

\section{Temporal profiles of regional CBF recorded by ASL}

To explore CBF in deep brain structures after ACAS, we performed ASL pre- and post-ACAS. On the AC side, cortical and subcortical CBF gradually decreased up to $28 \mathrm{~d}$ after ACAS (Fig. 2C-E). Notably, subcortical CBF levels were consistently lower than cortical CBF at both the bregma and hippocampal levels. At the bregma level, subcortical CBF was $17 \%$ of the baseline $\mathrm{CBF}$ and the cortical CBF was $24 \%$ on the right AC side at day 28 . On the left microcoil side, this tendency was also observed; at the bregma level, the subcortical CBF was $38 \%$ and the cortical CBF was $43 \%$ at day 28 . Furthermore, cortical and subcortical CBF levels on the AC side tended to be lower compared with those on the microcoil side after 14 and $28 \mathrm{~d}$ post-ACAS (Fig. 2C-E). The right subcortical areas on the AC side were most vulnerable to deranged hemodynamics after ACAS.

\section{Brain MRI showed fresh cerebral infarction}

Diffusion- and T2-weighted images showed multiple high-intensity signal areas in the $\mathrm{CC}, \mathrm{CPu}, \mathrm{IC}$, and hippocampal fimbria (HF) but not in the cerebral cortex at day 8 after ACAS. The ADC map showed low values in the same areas, indicating the development of fresh infarcts. Moreover, TOF MRA showed an absence in signal from the right internal carotid artery (ICA) and the middle cerebral artery (MCA), reflecting that the flow speed or volume decreased in the right ICA and MCA (Fig. 3).

\section{Histological changes}

The BCAS group did not reveal any infarcts throughout the brain after operation, as previously reported (Shibata et al., 2004). However, in the ACAS group, $88 \%$ of mice showed ischemic stroke at $14 \mathrm{~d}$ after operation $(n=8)$, and $75 \%$ of mice at $32 \mathrm{~d}$ after operation $(n=8)$. Multiple infarcts developed in subcorti-

$\mathbf{L}$

$A D C$ $\mathbf{R}$
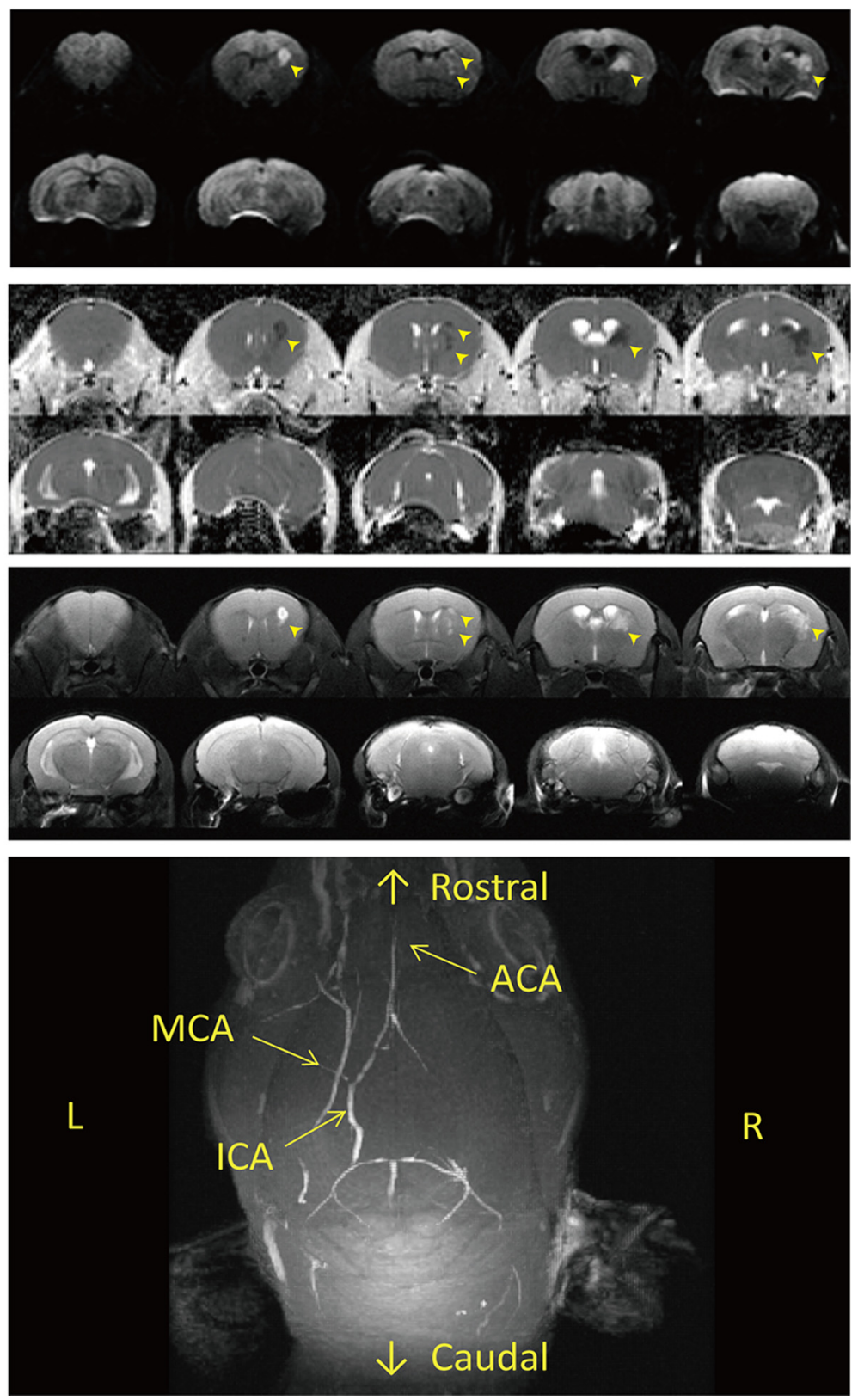

Figure 3. Multiple subcortical infarcts on 7 tesla brain MRI. Representative brain MRI of an ACAS mouse at $8 \mathrm{~d}$ after operation. Serial coronal sections show fresh cerebral infarcts at the paramedian part of the $\mathrm{CC}, \mathrm{CPu}, \mathrm{HF}$, and IC (yellow arrowheads) as high-intensity signal areas in diffusion-weighted images (DWI) and $\mathrm{T}_{2}$-weighted images (T2WI) and as low-value areas in $A D C$ maps. The flow signal of the right ICA and MCA was lacking on the MRA image. ACA, anterior cerebral artery; $L$, left; $R$, right.

cal areas such as the CC, CPu, IC, and HF, in $81 \%$ of mice $(13 / 16)$ on only the right $\mathrm{AC}$ side at 14 and $32 \mathrm{~d}$ after operation: ischemic stroke developed in 11 mice (69\%) in the CC, 7 mice (44\%) in the IC, 10 mice $(63 \%)$ in the $\mathrm{HF}$, and 11 mice $(69 \%)$ in the $\mathrm{CPu}$. Cortical infarcts appeared in five mice (31\%), and accounted for $15.6 \%$ of all infarcts developed in ACAS mice, at 14 and $32 \mathrm{~d}$ after operation. There were numerous accumulations of Iba1-positive microglia and GFAP-positive astrocytes in all infarctions apparent after hematoxylin and eosin staining (Fig. 4). Hippocampal neuronal loss was seen only on the right AC side in $69 \%$ of ACAS mice, but not the left microcoil side. Activated microglia surrounded the area of neuronal loss in the hippocampus (Fig. 5). 
A

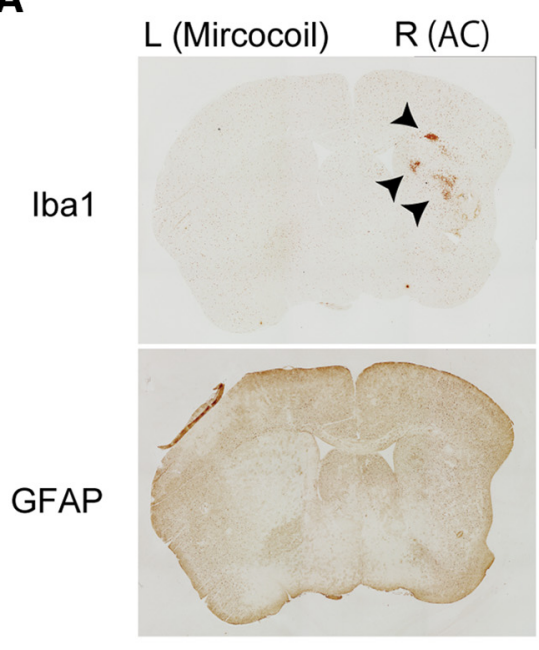

B

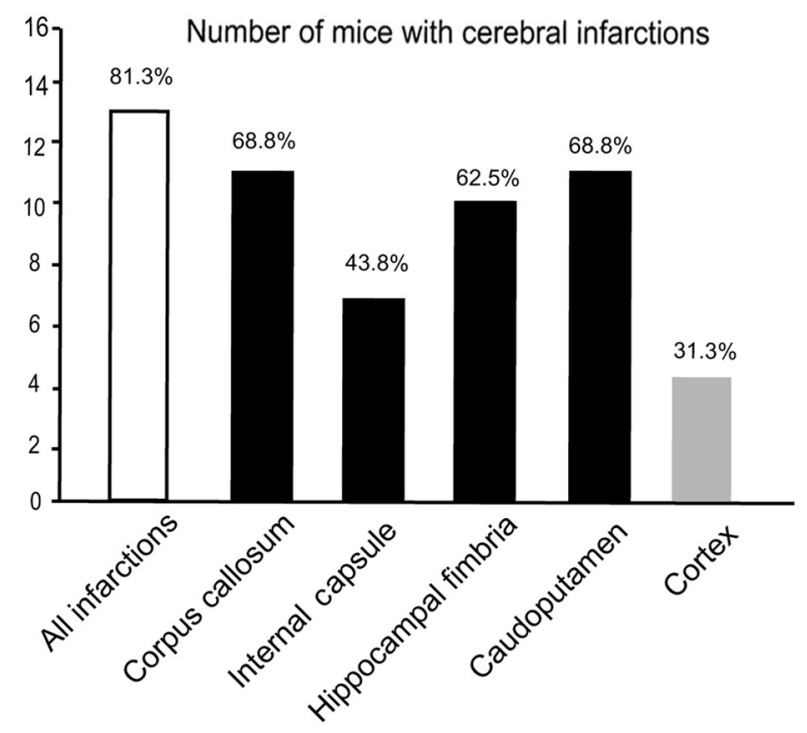

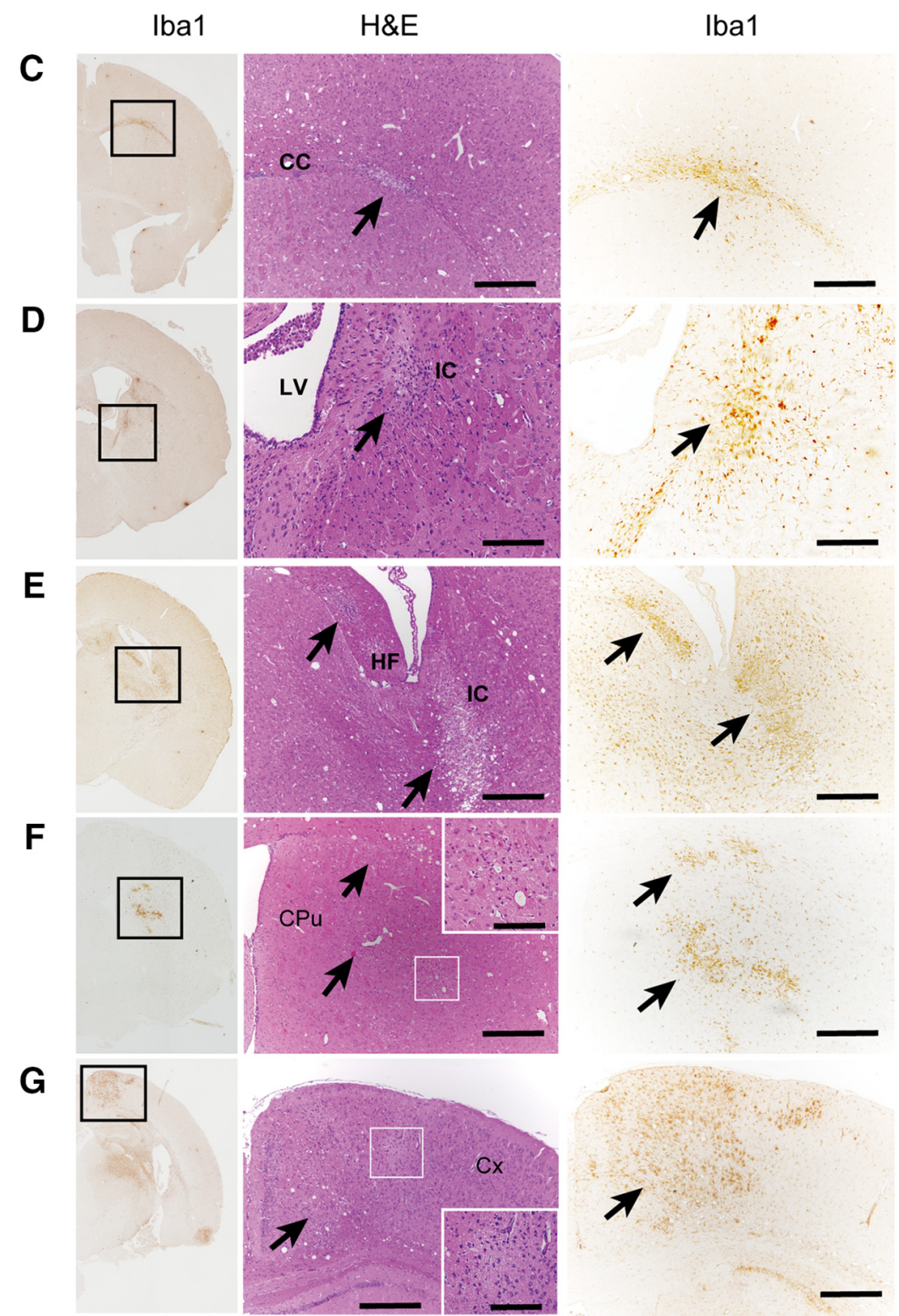


In contrast, no infarcts were present on the microcoil side by $32 \mathrm{~d}$ after operation. Histopathological analysis of the $\mathrm{CC}$ and the anterior commissure with Klüver-Barrera staining showed grade 0 or grade 1 damage at $14 \mathrm{~d}$ after operation, but after $32 \mathrm{~d}$, moderate to severe rarefaction (grade 2-3) occurred in these regions. In contrast, the WM changes in the optic tract were less severe than in the CC and the anterior commissure until day 32 (Fig. $6 A)$. The demyelination in the CC was accompanied by significant proliferation of GFAP-positive astrocytes and Iba1-positive microglia in ACAS mice compared with sham-operated mice. The number of GFAP-positive astrocytes was similarly greater than sham mice at days 14 and 32, while the Iba1-positive microglia continued to increase from day 14 to 32 . The amount of GST- $\pi$-positive oligodendrocytes tended to decrease in the ACAS mice compared with the sham-operated mice at days 14 and 32. In addition, in ACAS mice, SMI32-positive damaged axons significantly increased at day 32 compared with those at day 14 after ACAS and sham-operated mice (Fig. 6B). The histological findings of sham-operated mice were comparable to those of mice with UCAS or UCAgO, supporting the findings that UCAS or UCAgO induced only minimal changes in CBF levels.

\section{Rotarod test and wire hang test for motor function assessment}

The rotarod test showed that latency to fall was significantly shorter in the ACAS group at day 14, compared with the sham group, indicating that motor coordination and balance were significantly impaired in the ACAS mice (Fig. 7A). Similarly, a significantly shorter latency to fall was found in wire hang testing in the ACAS group compared with the sham-operated mice at day 14 , indicating that muscle strength was significantly impaired in ACAS mice (Fig. 7B).

\section{Y-maze test for spatial working memory and spontaneous activity assessment}

We examined whether the ACAS mice showed impairment in spatial working memory and spontaneous activity using the Y-maze test. In the ACAS group, the percentage of alternation behaviors (used as an indicator of spatial working memory) was not decreased at day 14 but significantly decreased at day 28 , compared with the UCAS, UCAgO, or sham-operated mice. This indicates that ACAS mice specifically show spatial working memory impairment, suggesting that combinational placement of a microcoil and an AC on each respective CCA induces a synergistic effect but that unilateral microcoil or AC alone is not sufficient to induce working memory impairment. The number of arm entries of ACAS mice tended to increase compared with that of the UCAS, UCAgO, or sham-operated mice at days 14 and 28 after each operation. This indicated that spontaneous activity may be increased, rather than decreased, as a result of hyperactivity in ACAS mice (Fig. 7C).

\footnotetext{
$\leftarrow$

Figure 4. Multiple subcortical infarcts were induced in the AC side of ACAS mice. $A$, Representative images of coronal brain section immunostained for Iba1 (top) and GFAP (bottom). Arrowheads indicate infarct formation. $B, A$ histogram showing the number and percentage of ACAS mice $(n=16)$ that developed cerebral infarcts in the $C C, I C, H F, C P u$, and cerebral cortex $(\boldsymbol{C x})$. Infarcts at the $\mathrm{CC}(\boldsymbol{C}), \mathrm{IC}(\boldsymbol{D}), \mathrm{HF}$ and IC $(\boldsymbol{E}), \mathrm{CPu}(\boldsymbol{F})$, and $\mathrm{Cx}(\boldsymbol{G})$ were indicated. Representative images of the right hemisphere with several infarcts visualized by immunostaining for Iba1 (left), staining for H\&E (middle), and immunostaining for lba1 (right) of marked areas on the left side. The insets in the middle of $\boldsymbol{F}$ and $\boldsymbol{G}$ are the enlarged images of white-marked regions. Arrows indicate infarct changes. Scale bars: $200 \mu \mathrm{m}$; insets, $100 \mu \mathrm{m}$. LV, lateral ventricle; $L$, left; $R$, right.
}

\section{Morris water maze test for reference memory assessment}

We next examined whether the ACAS mice showed spatial learning and reference memory impairment using the Morris water maze test. The ACAS mice exhibited longer escape latencies than the sham-operated mice throughout the acquisition phase (Fig. $8 A$ ). In particular, ACAS mice failed to learn platform location during the second half of the acquisition phase. The swimming speed did not differ between four groups during the acquisition phase (Fig. $8 B$ ). In the probe trial, ACAS mice spent a similar duration of time in every quadrant, including Zone 1 (the target quadrant), while sham-operated mice spent a significantly greater time in Zone 1 than in the other quadrants (Fig. 8C). Examination of traces of swimming paths in the probe trial showed that sham-operated mice selectively searched the correct quadrant but ACAS mice did not (Fig. $8 D$ ). These results indicated that ACAS mice show hippocampus-dependent reference learning and memory impairment, reflecting existing hippocampal neuronal loss. The UCAS mice exhibited significantly shorter escape latencies than the ACAS mice throughout the acquisition phase and spent a significantly greater time in the target quadrant in the probe trial, while the UCAgO mice had a tendency for shorter escape latencies than the ACAS mice $(p=0.06)$ and spent a significantly greater time in the target quadrant in the probe trial (Fig. 8). These results indicated that combinatorial placement of a microcoil and an AC on each respective CCA induced synergistic effects on spatial learning and reference memory impairment.

\section{Discussion}

By applying a microcoil on the left CCA and an AC on the right CCA, we have successfully established a novel mouse model of long-term hypoperfusion (named the ACAS model), which results in a gradual decrease in CBF in both hemispheres, with the maximum decrease in the right subcortical area. Subsequently, multiple ischemic strokes developed in the right subcortical area, including the deep WM and the hippocampus, which are areas vulnerable to cerebral ischemia in humans. In the left hemisphere (microcoil side), CBF decrease was milder but WM rarefaction and gliosis were induced instead of ischemic stroke. Based on these histological changes, the ACAS model showed motor incoordination and neuromuscular weakness at $14 \mathrm{~d}$ and cognitive impairment at $28 \mathrm{~d}$ after operation. The ACAS model thus represents a novel animal model that replicates predominant WM infarcts accompanied by motor deficits and dementia, namely subcortical VCI.

The volume of WM in rodents, such as mice and rats, occupies only $10-15 \%$ of whole brain. Therefore, replicating selective WM infarcts in rodents possesses considerable difficulties. Thus far, most existing mouse models of ischemic stroke, such as the permanent/transient middle cerebral artery occlusion model, predominantly result in infarct damage to gray matter regions. Thus, previous histopathological studies of pharmacological agents against acute stroke in rodent models have mainly focused on evolutional changes in microscopic morphology of the gray matter, especially in the cerebral cortex (Dewar et al., 1999). This may explain the failure of clinical trials using neuroprotective drugs for the treatment of acute stroke, contrasting with $>4000$ publications describing 700 agents found to be neuroprotective in preclinical studies (Kaste, 2005). For example, NMDA receptor and $\mathrm{Ca}^{2+}$ receptor antagonists have so far failed in clinical evaluation for the treatment of acute ischemic stroke (Davis et al., 2000; Albers et al., 2001; Horn and Limburg, 2001; Sacco et al., 2001), despite preclinical promise. As only neurons have NMDA recep- 
A
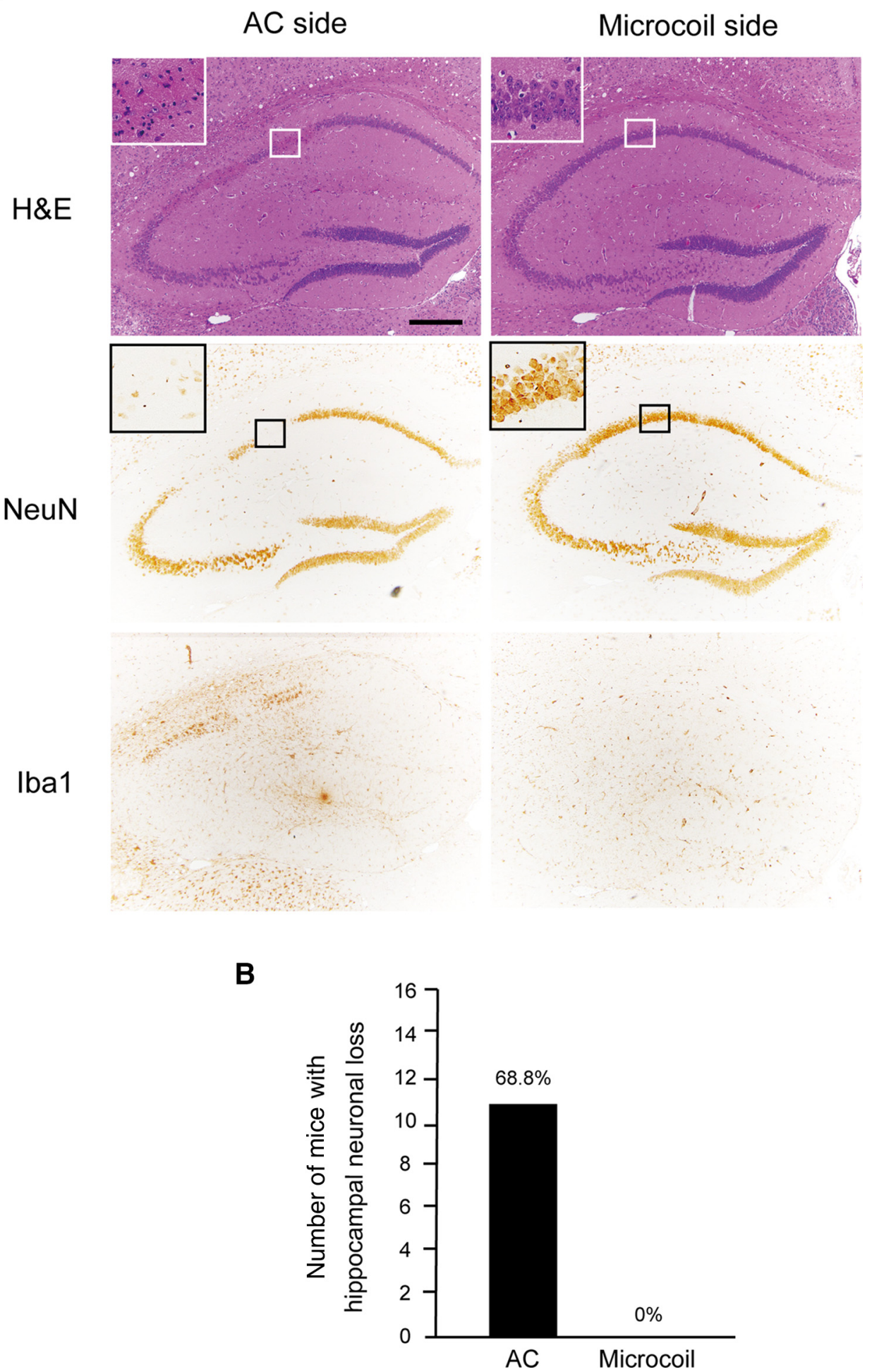

Figure 5. Hippocampal neuronal loss was seen only at the AC side of ACAS mice. $A$, Representative images of H\&E staining and immunohistochemistry for NeuN and Iba1 of the hippocampus in the right ( $\mathrm{AC}$ side) and left (microcoil side) hemisphere. The inset shows a magnified image of the indicated area. Scale bar, $200 \mu \mathrm{m}$. B, Histogram showing percentage of mice with hippocampal neuronal loss in the right (AC side) and left (microcoil side) hemisphere of the ACAS mice $(n=16)$.

tors, and voltage-sensitive $\mathrm{Ca}^{2+}$ channels are predominantly found in the cortex, cortical ischemic injury (e.g., neuronal injury or neurotoxicity) is mainly caused by excessive activation of NMDA receptors with excess glutamate and $\mathrm{Ca}^{2+}$ over influx into neurons (Kitagawa, 2012). However, in the WM, nodes of Ranvier are rich in voltage-dependent $\mathrm{Na}^{+}$channels. Therefore, the NMDA receptor and $\mathrm{Ca}^{2+}$ receptor antagonists give the impression of having little effect on the WM ischemic injury, comprising of edema through excess influx of $\mathrm{Na}^{+}$to the axons.

Relatively few animal stroke models accurately replicate WM infarct damage. Among them is an endothelin-1 (ET-1) injection model, in which ET-1, a potent and long-acting venous and ar- 
A
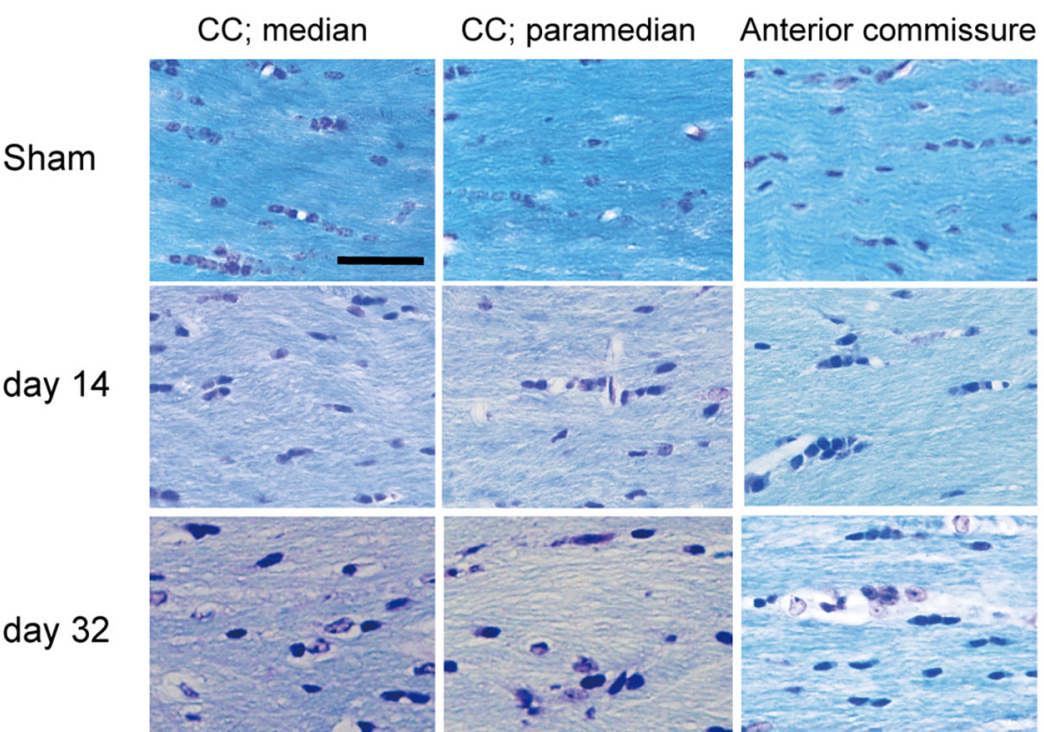

Optic tract
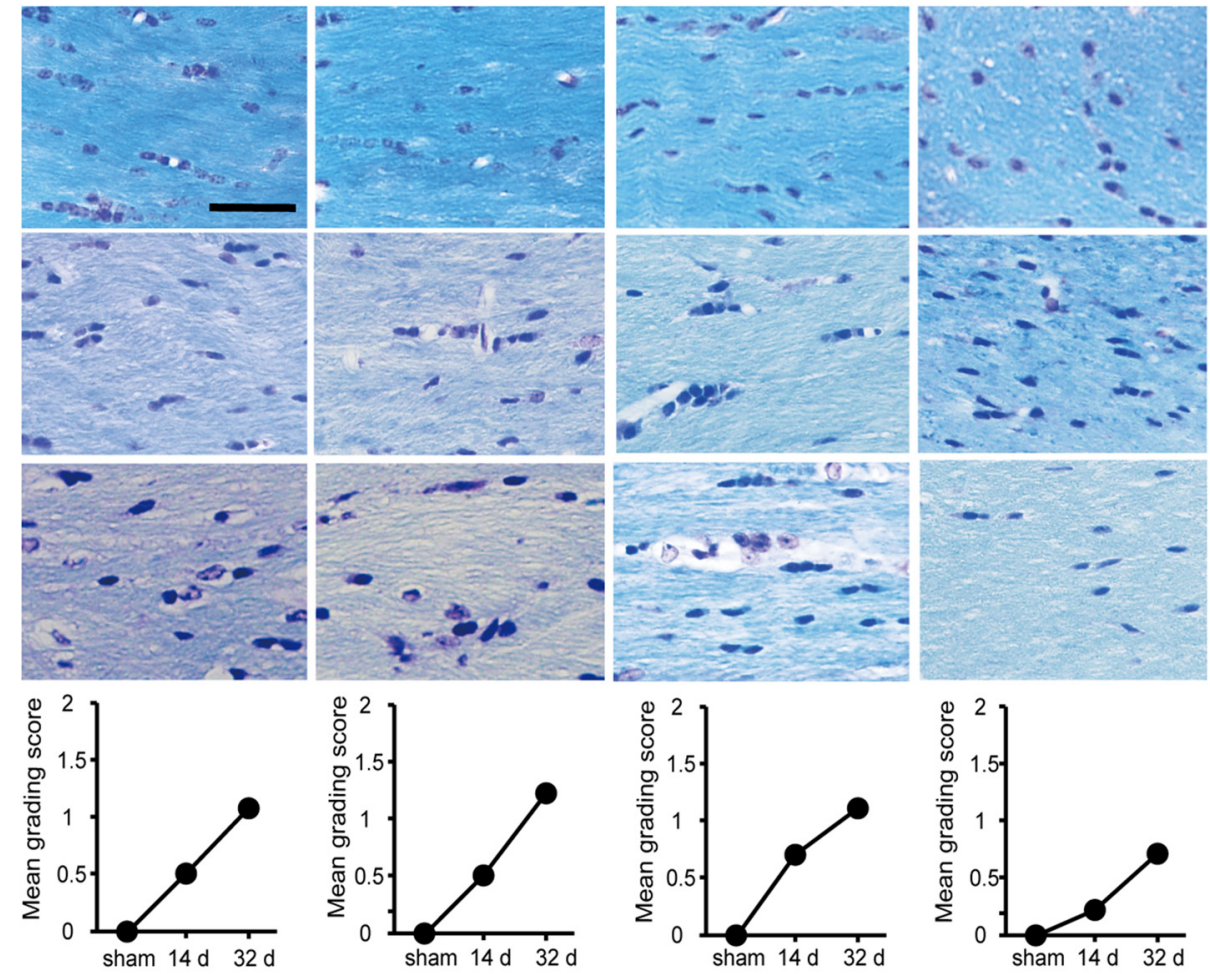

B

GFAP
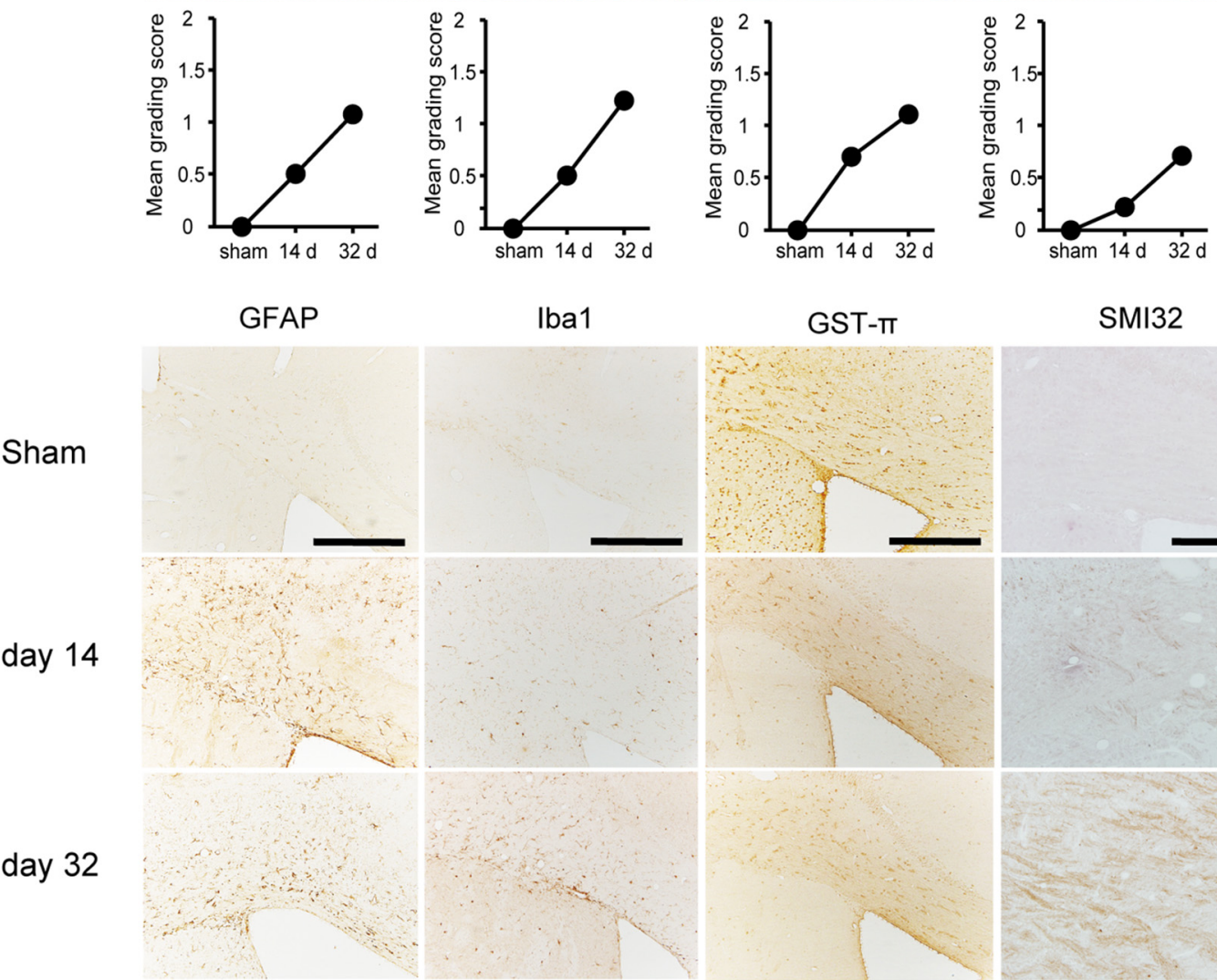

Iba1

GST-T

SMI32
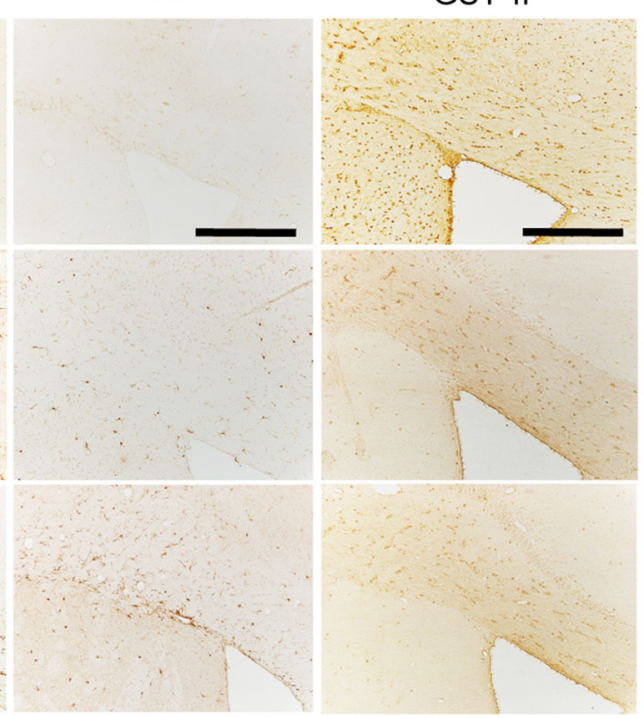

(\%)

(\%)

(\%)
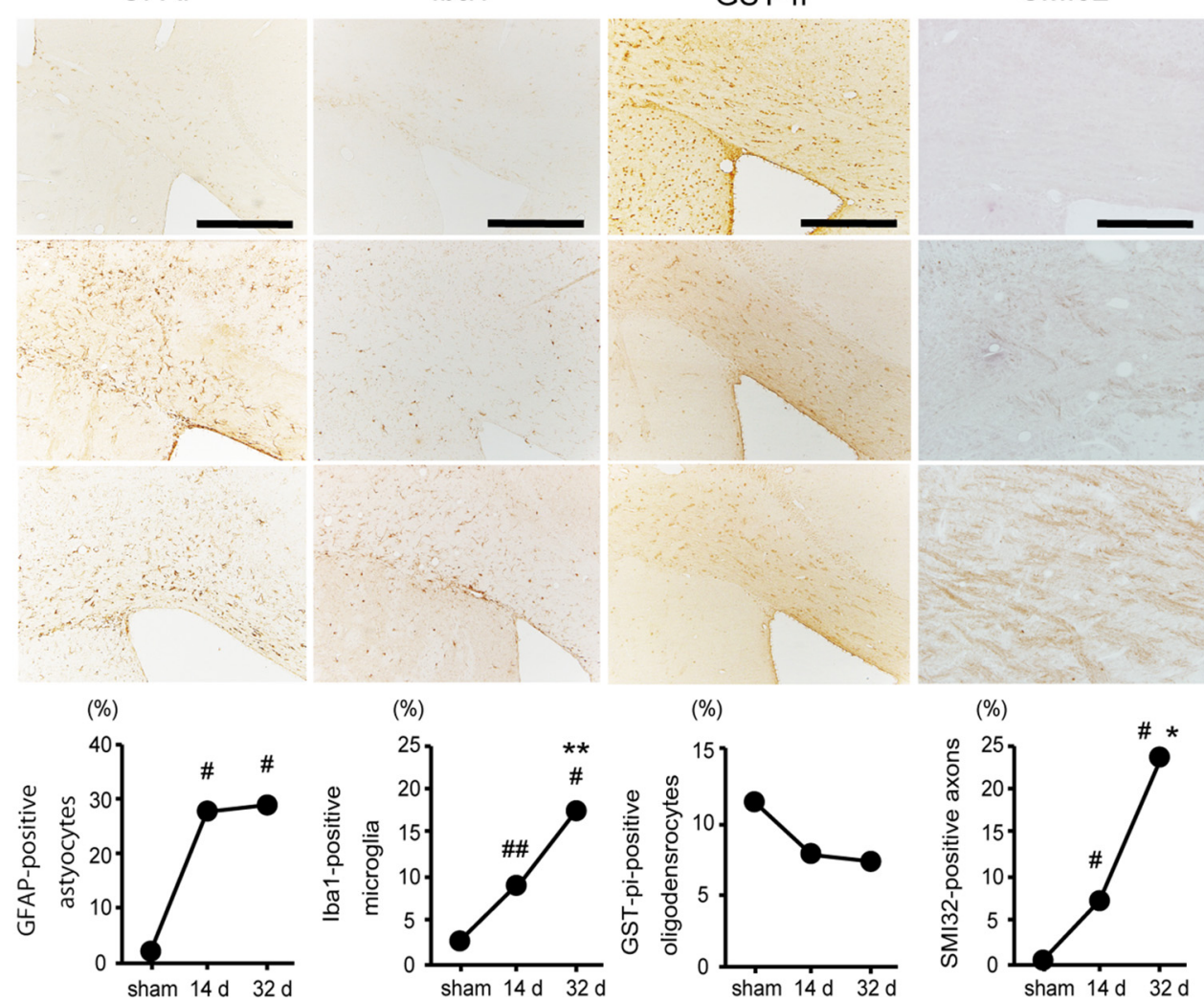

Figure 6. WM rarefaction, gliosis, and axonal damage were seen in the microcoil side of ACAS mice. $A$, Representative photomicrographs of the Klüver-Barrera staining of the medial and paramedial part of the CC, anterior commissure, and optic tract from the brain of sham-operated mice and from the left hemisphere (microcoil side) of ACAS mice at days 14 and 32 post-ACAS. Scale bar, $50 \mu \mathrm{m}$. Lower line graphs show temporal profiles of the grade of WM changes in the respective WM regions. $\boldsymbol{B}$, Representative photomicrographs of immunostain for GFAP, Iba1, GST- $\pi$, and SMI32 at the paramedial part of CC from the brain of the sham-operated mice and from the left hemisphere (microcoil side) of ACAS mice at days 14 and 32 post-ACAS. Scale bars: GFAP, Iba1, GST- $\pi, 200 \mu$ m; SMI32, $100 \mu \mathrm{m}$. Lower line graphs show temporal profiles of the percentage of numerical densities of the GFAP-positive astrocytes, Iba1-positive microglia, GST- $\pi$-positive oligodendrocytes, and SMI32-positive axons from the brains of sham-operated mice and the left hemisphere (microcoil side) of ACAS mice at days 14 and 32 post-ACAS. \#p $<0.01$ versus sham; \#\#p $<0.05$ versus sham; ${ }^{*} p<0.01$ versus 14 d; ${ }^{* *} p<0.05$ versus $14 \mathrm{~d}$. 
A

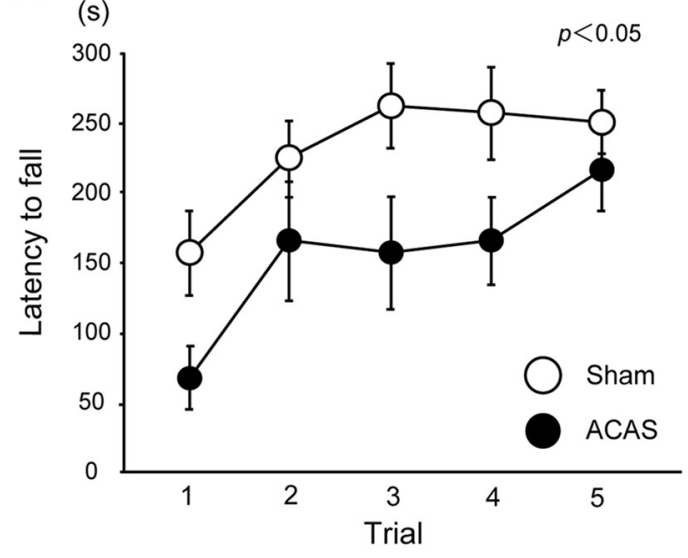

B

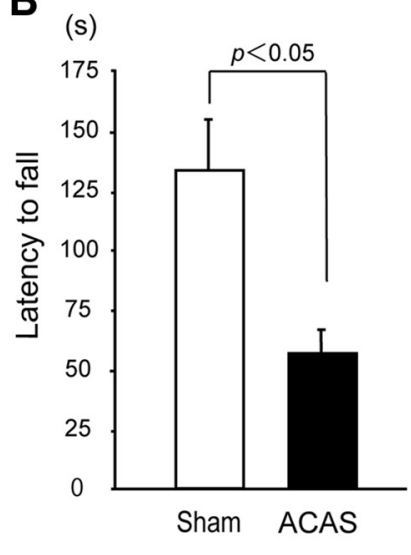

C
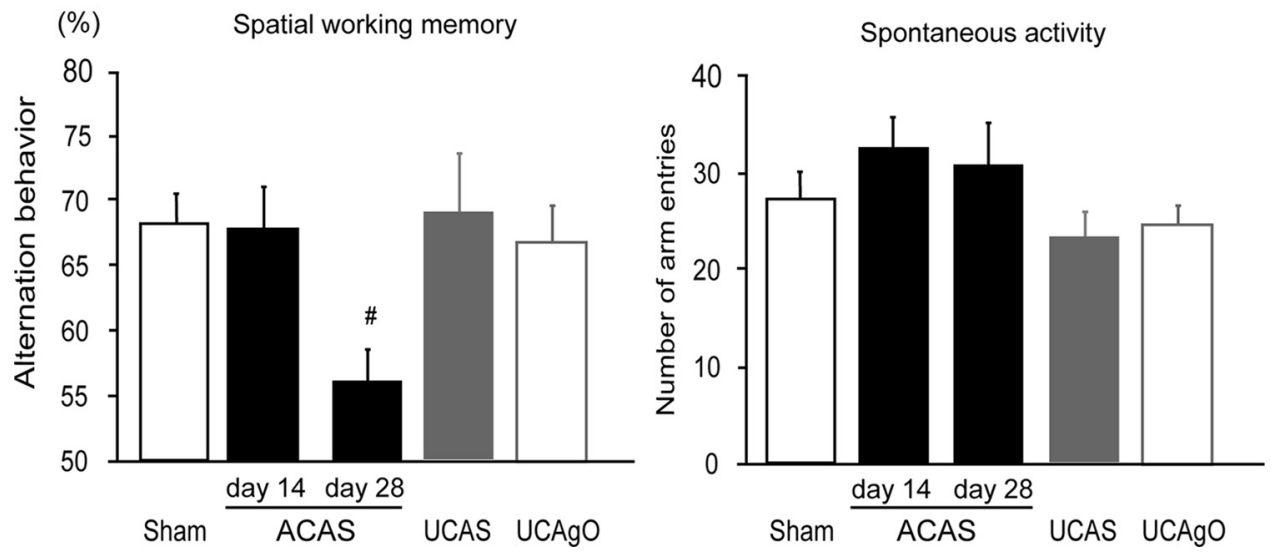

Figure 7. Behavioral performance of ACAS mice in rotarod, wire hang, and Y-maze tests. $\boldsymbol{A}$, Motor coordination and balance tested with five consecutive trials of rotarod test on day 14 . Data were analyzed by two-way repeated-measures ANOVA. B, Neuromuscular strength tested with wire hang test on day 14 . $\boldsymbol{C}$, Spatial working memory and spontaneous activity were tested with Y-maze test on day 14 or day 28 . All the behavioral studies were performed by using the ACAS mice $(n=9)$, sham-operated mice $(n=15)$, UCAS mice $(n=6)$, and UCAg0 mice $(n=6)$. \#p $<0.05$ versus sham. Error bars indicate mean \pm SEM.

terial vasoconstrictor (Masaki and Yanagisawa, 1992), is injected into WM to produce focal subcortical stroke (Gilmour et al., 2004). This approach may directly induce focal infarction in deep brain compartments. However, there are some drawbacks in this model. Craniectomy is necessary for stereotaxic application of ET-1, which may cause trauma along the needle track, possibly leading to myelin disruption without overt loss of myelin (Hughes et al., 2003). In addition, ET-1, ET-1-converting enzyme, and two subtypes of ET-1 receptors are expressed not only on vascular endothelial cells but also on neurons and astrocytes in the brain (Nakagomi et al., 2000; Naidoo et al., 2004); therefore, ET-1 may induce astrocytosis and interfere with axonal regeneration in neural repair experiments (Uesugi et al., 1996, 1998). Alternatively, WM stroke animal models have been generated by anterior choroidal artery occlusion in rats and pigs (He et al., 1999, 2000; Tanaka et al., 2008) but have been undermined by the inherent technical difficulties of intracerebral artery occlusion in such animals.

The current mouse model induced multiple infarcts in the paramedian part of CC, CPu, IC, and HF. These sites correspond approximately with the internal watershed territory, which is located in the WM along and slightly above the lateral ventricle between the deep and superficial arterial systems of the MCA (Dorr et al., 2007). The CC, IC, and CPu at the bregma level are located between perfusion territories of MCA branches, namely MCA cortical branches and anterior/posterior striate arteries. The HF, CC, IC, and CPu at the hippocampal level are located between MCA cortical branches and ICA branches including the dorsolateral thalamic and anterior choroidal arteries (Dorr et al., 2007). Such arterial border zone areas were therefore most susceptible to deranged hemodynamics in this model.

The existing rodent models of chronic cerebral hypoperfusion partially recapitulate subcortical VCI by developing WM rarefaction. For instance, the BCAS mouse model shows WM-specific damage such as rarefaction, glial activation, and axonal damage (Shibata et al., 2004; Coltman et al., 2011). This model is thought to be the most promising model of VCI (Bink et al., 2013) as working memory is reproducibly impaired at $28 \mathrm{~d}$ after microcoil placement on bilateral CCAs (Shibata et al., 2007; Coltman et al., 2011). However, other characteristics of subcortical VCI, such as WM or striatal lacunar infarcts, as well as gradual CBF reduction, are not replicated. The BCAS mouse model and two-vessel occlusion rat model are generated by manipulations of the CCAs; however, its inherent limitations include an acute drop in CBF, which is followed by compensatory recovery of CBF (Ihara and Tomimoto, 2011). This factor may therefore lead to contention in determining whether WM rarefaction has been induced by acute drop of CBF or by chronic hypoperfusion (Kitamura et al., 2012). 
A

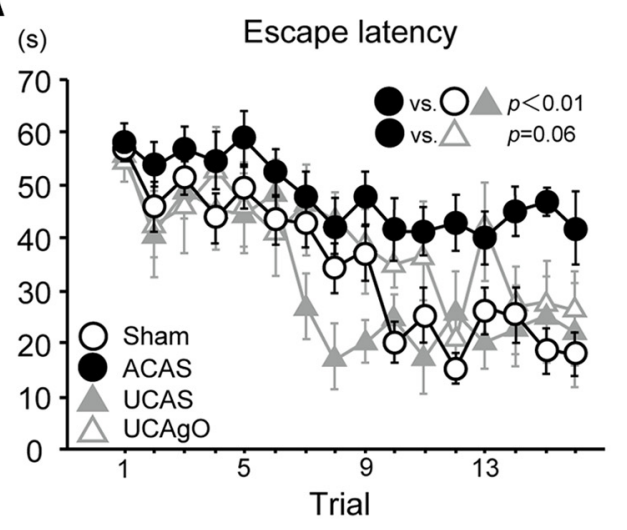

B

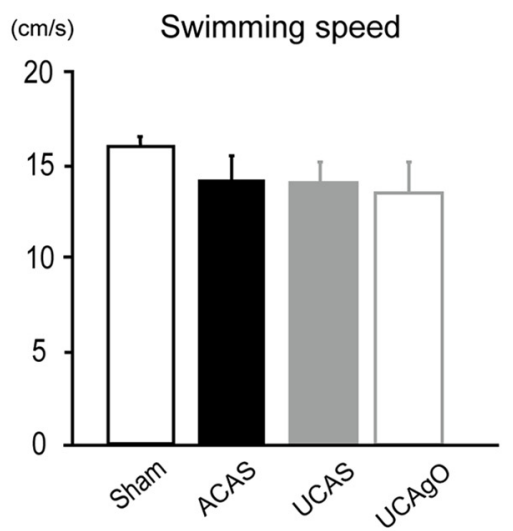

C

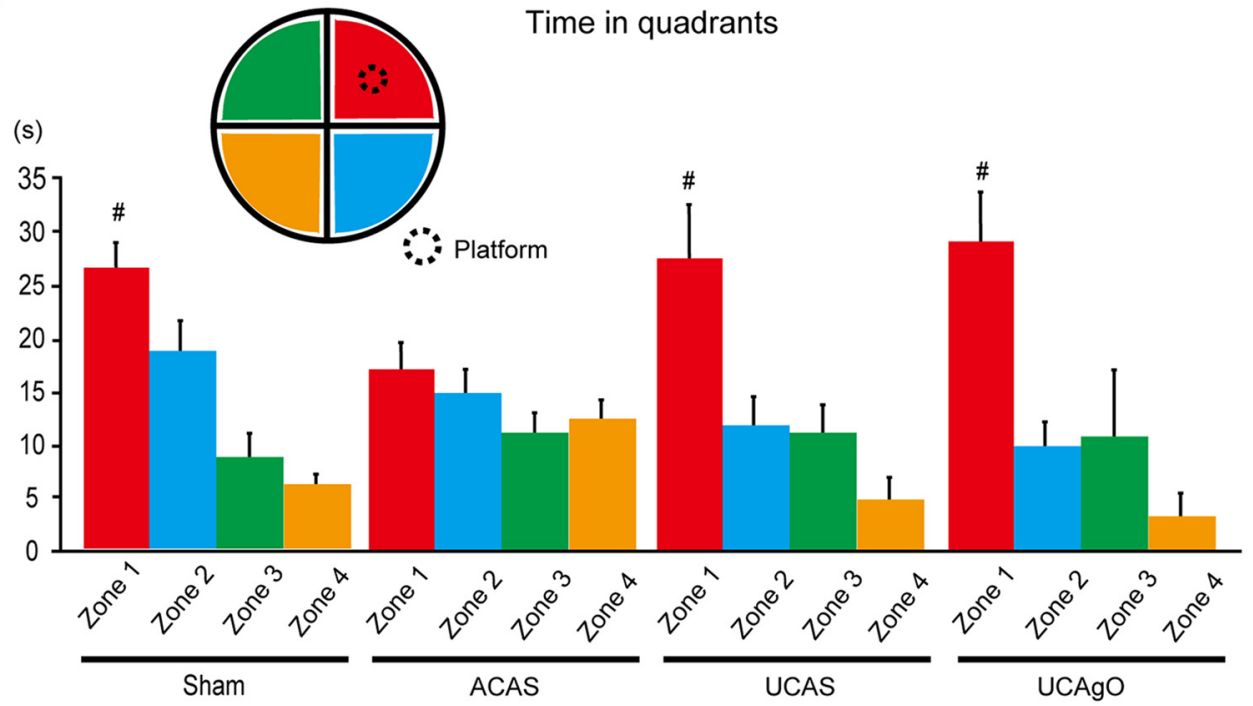

D

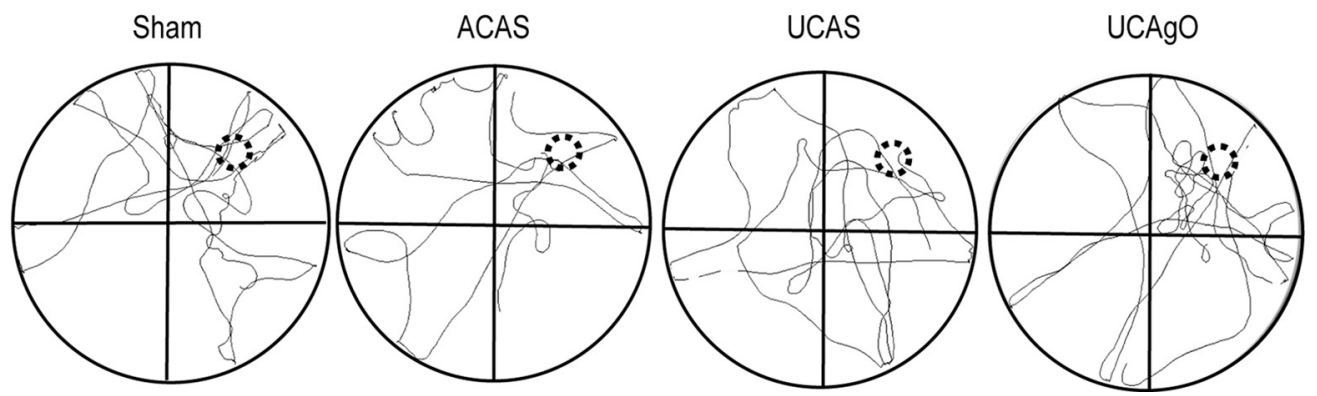

Figure 8. Behavioral performance of ACAS mice in the Morris water maze test. $\boldsymbol{A}$, Time course of escape latency from day 1 to 4 of sham-surgery mice, ACAS mice, UCAS mice, and UCAg0 mice in the acquisition phase is shown. Data were analyzed by two-way repeated-measures ANOVA. $\boldsymbol{B}$, Mean swimming speed in the acquisition phase was not different between the four groups. $\boldsymbol{C}$, Histogram showing the time spent in each quadrant in the probe trial. \#p $<0.05$ versus Zones $2-4$. D, Representative images of traces of swimming paths of four groups in the probe trial. The Morris water maze test was performed by using sham-surgery mice $(n=15)$, ACAS mice $(n=9)$, UCAS mice $(n=6)$, and UCAg0 mice $(n=6)$. Error bars indicate mean \pm SEM.

In contrast, the current mouse model more precisely replicates the human disease characteristics in terms of temporal CBF profile and ischemic brain regions. Subcortical VCI is characterized by decompensated ischemic changes, which gradually occur as age advances, subsequently leading to chronic ischemic changes in the WM and basal ganglia with resultant cognitive impairment. An MRI-pathological correlation study of VCI cases has suggested that the WM pathological damage consists of heterogeneous combinations of myelin loss, axonal loss, scattered small infarcts, and astrogliosis (Udaka et al., 2002; Jellinger, 2007). Therefore, the current model more precisely mimics such disease processes and characteristics of subcortical VCI and can be used to develop a novel strategy to tackle VCI.

One of the most plausible explanations for the successful generation of ischemic lacunar-like small infarctions in the current hypoperfusion model was that gradual CBF reduction might have circumvented a strong compensatory mechanism. There was a clear contrast in the brain-surface CBF profiles between the ACAS and BCAS models; the CBF reduction reached $60 \%$ of the baseline level, with gradual reduction by $7 \mathrm{~d}$ after ACAS operation, while CBF in the BCAS model started to recover as early as the next day after the operation (see Fig. $2 B$ ). The gradual CBF 
reduction was successfully generated in the rat two-vessel gradual occlusion model by using the ACs, but the degree of CBF reduction was milder in rats because of the relatively well developed posterior communicating arteries, compared with the C57BL/6 mice (Kitamura et al., 2012). In the current model, therefore, the compensatory mechanism may have been minimized and CBF reduction maintained for a period of time sufficient enough to induce infarctions in the areas with an end-artery vascular supply.

Another advantage of using the current model would be rightto-left comparison of efficacy of certain drugs to ischemia because of the difference in ischemic depth between hemispheres. The right hemisphere mimics characteristics of multiple subcortical infarcts and the left hemisphere those of leukoaraiosis, sequelae to chronic cerebral hypoperfusion. The prompt and reproducible generation of small subcortical infarcts, as well as leukoaraiosis, in a timely manner would be an advantage in the analysis of subcortical VCI pathophysiology and search for drugs that target WM changes.

Subcortical VCI can be accompanied by a wide range of neurological deficits. Symptomatic lacunes may present with acute sensorimotor deficits (pure motor hemiplegia, pseudobulbar palsy, and other lacunar syndromes) before subacute manifestations, such as cognitive impairment, personality and mood disorders, develop (Román et al., 2002). Our current study demonstrates that ACAS-induced impairment in locomotor activity at $14 \mathrm{~d}$ after operation and working and reference memory impairment later at $28 \mathrm{~d}$. This time course of phenotype development in the ACAS model may correspond with the clinical complications of subcortical VCI.

This study has a limitation in that ACAS mice did not develop microvasculature pathology, while most human VCI result from pathology of microvasculature due to hypertension, diabetes, and genetic factors such as cerebral arteriopathy with subcortical infarcts and leukoencephalopathy. Further analysis using the ACAS procedure applied to various model mice with some liferelated or genetic vascular risk factors including hypertension, diabetes, obesity, and dyslipidemia is thus warranted.

In summary, a novel mouse model of subcortical VCI has been established, which causes gradual CBF reduction, accompanied by small lacunar infarcts in the areas supplied by end arteries, with subsequent cognitive impairment. We therefore believe this model could be used in the exploration of new treatments for VCI and coexisting neurological complications.

\section{References}

Albers GW, Goldstein LB, Hall D, Lesko LM (2001) Aptiganel hydrochloride in acute ischemic stroke: a randomized controlled trial. JAMA 286: 2673-2682. CrossRef Medline

Ayata C, Dunn AK, Gursoy-Ozdemir Y, Huang Z, Boas DA, Moskowitz MA (2004) Laser speckle flowmetry for the study of cerebrovascular physiology in normal and ischemic mouse cortex. J Cereb Blood Flow Metab 24:744-755. CrossRef Medline

Bink DI, Ritz K, Aronica E, van der Weerd L, Daemen MJ (2013) Mouse models to study the effect of cardiovascular risk factors on brain structure and cognition. J Cereb Blood Flow Metab 33:1666-1684. CrossRef Medline

Coltman R, Spain A, Tsenkina Y, Fowler JH, Smith J, Scullion G, Allerhand M, Scott F, Kalaria RN, Ihara M, Daumas S, Deary IJ, Wood E, McCulloch J, Horsburgh K (2011) Selective white matter pathology induces a specific impairment in spatial working memory. Neurobiol Aging 32: 2324.e7-2324.e12. CrossRef Medline

Davis SM, Lees KR, Albers GW, Diener HC, Markabi S, Karlsson G, Norris J (2000) Selfotel in acute ischemic stroke: possible neurotoxic effects of an NMDA antagonist. Stroke 31:347-354. CrossRef Medline

Dewar D, Yam P, McCulloch J (1999) Drug development for stroke: impor- tance of protecting cerebral white matter. Eur J Pharmacol 375:41-50. CrossRef Medline

Dong YF, Kataoka K, Tokutomi Y, Nako H, Nakamura T, Toyama K, Sueta D, Koibuchi N, Yamamoto E, Ogawa H, Kim-Mitsuyama S (2011) Beneficial effects of combination of valsartan and amlodipine on salt-induced brain injury in hypertensive rats. J Pharmacol Exp Ther 339:358-366. CrossRef Medline

Dorr A, Sled JG, Kabani N (2007) Three-dimensional cerebral vasculature of the CBA mouse brain: a magnetic resonance imaging and micro computed tomography study. Neuroimage 35:1409-1423. CrossRef Medline

Durukan A, Tatlisumak T (2007) Acute ischemic stroke: overview of major experimental rodent models, pathophysiology, and therapy of focal cerebral ischemia. Pharmacol Biochem Behav 87:179-197. CrossRef Medline

Fisher CM (1968) The arterial lesions underlying lacunes. Acta Neuropathol 12:1-15. CrossRef Medline

Gilmour G, Iversen SD, O'Neill MF, Bannerman DM (2004) The effects of intracortical endothelin-1 injections on skilled forelimb use: implications for modelling recovery of function after stroke. Behav Brain Res 150:171183. CrossRef Medline

Gladstone DJ, Black SE, Hakim AM; for the Heart and Stroke Foundation of Ontario Centre of Excellence in Stroke Recovery (2002) Toward wisdom from failure: lessons from neuroprotective stroke trials and new therapeutic directions. Stroke 33:2123-2136. CrossRef Medline

Hainsworth AH, Markus HS (2008) Do in vivo experimental models reflect human cerebral small vessel disease? A systematic review. J Cereb Blood Flow Metab 28:1877-1891. CrossRef Medline

Hattori Y, Kitamura A, Nagatsuka K, Ihara M (2014a) A novel mouse model of ischemic carotid artery disease. PLoS One 9:e100257. CrossRef Medline

Hattori Y, Kitamura A, Tsuji M, Nagatsuka K, Ihara M (2014b) Motor and cognitive impairment in a mouse model of ischemic carotid artery disease. Neurosci Lett 581:1-6. CrossRef Medline

He Z, Yamawaki T, Yang S, Day AL, Simpkins JW, Naritomi H (1999) Experimental model of small deep infarcts involving the hypothalamus in rats: changes in body temperature and postural reflex. Stroke 30:27432751; discussion 2751. CrossRef Medline

He Z, Yang SH, Naritomi H, Yamawaki T, Liu Q, King MA, Day AL, Simpkins JW (2000) Definition of the anterior choroidal artery territory in rats using intraluminal occluding technique. J Neurol Sci 182:16-28. CrossRef Medline

Horn J, Limburg M (2001) Calcium antagonists for ischemic stroke: a systematic review. Stroke 32:570-576. CrossRef Medline

Hughes PM, Anthony DC, Ruddin M, Botham MS, Rankine EL, Sablone M, Baumann D, Mir AK, Perry VH (2003) Focal lesions in the rat central nervous system induced by endothelin-1. J Neuropathol Exp Neurol 62: 1276-1286. Medline

Ihara M, Kalaria RN (2014) Understanding and preventing the development of post-stroke dementia. Expert Rev Neurother 14:1067-1077. CrossRef Medline

Ihara M, Tomimoto H (2011) Lessons from a mouse model characterizing features of vascular cognitive impairment with white matter changes. J Aging Res 2011:978761. CrossRef Medline

Jellinger KA (2007) The enigma of vascular cognitive disorder and vascular dementia. Acta Neuropathol 113:349-388. CrossRef Medline

Jiwa NS, Garrard P, Hainsworth AH (2010) Experimental models of vascular dementia and vascular cognitive impairment: a systematic review. J Neurochem 115:814-828. CrossRef Medline

Kaste M (2005) Use of animal models has not contributed to development of acute stroke therapies: pro. Stroke 36:2323-2324. CrossRef Medline

Kim SG (1995) Quantification of relative cerebral blood flow change by flow-sensitive alternating inversion recovery (FAIR) technique: application to functional mapping. Magn Reson Med 34:293-301. CrossRef Medline

Kim SG, Tsekos NV (1997) Perfusion imaging by a flow-sensitive alternating inversion recovery (FAIR) technique: application to functional brain imaging. Magn Reson Med 37:425-435. CrossRef Medline

Kitagawa K (2012) Ischemic tolerance in the brain: endogenous adaptive machinery against ischemic stress. J Neurosci Res 90:1043-1054. CrossRef Medline

Kitamura A, Fujita Y, Oishi N, Kalaria RN, Washida K, Maki T, Okamoto Y, Hase Y, Yamada M, Takahashi J, Ito H, Tomimoto H, Fukuyama H, Takahashi R, Ihara M (2012) Selective white matter abnormalities in a 
novel rat model of vascular dementia. Neurobiol Aging 33:1012.e251012.e35. CrossRef Medline

Masaki T, Yanagisawa M (1992) Endothelins. Essays Biochem 27:79-89. Medline

Naidoo V, Naidoo S, Mahabeer R, Raidoo DM (2004) Cellular distribution of the endothelin system in the human brain. J Chem Neuroanat 27:87-98. CrossRef Medline

Nakagomi S, Kiryu-Seo S, Kiyama H (2000) Endothelin-converting enzymes and endothelin receptor B messenger RNAs are expressed in different neural cell species and these messenger RNAs are coordinately induced in neurons and astrocytes respectively following nerve injury. Neuroscience 101:441-449. CrossRef Medline

O'Collins VE, Macleod MR, Donnan GA, Horky LL, van der Worp BH, Howells DW (2006) 1,026 experimental treatments in acute stroke. Ann Neurol 59:467-477. CrossRef Medline

Pantoni L, Garcia JH (1995) The significance of cerebral white matter abnormalities 100 years after Binswanger's report. A review. Stroke 26: 1293-1301. CrossRef Medline

Richard Green A, Odergren T, Ashwood T (2003) Animal models of stroke: do they have value for discovering neuroprotective agents? Trends Pharmacol Sci 24:402-408. CrossRef Medline

Román GC, Erkinjuntti T, Wallin A, Pantoni L, Chui HC (2002) Subcortical ischaemic vascular dementia. Lancet Neurol 1:426-436. CrossRef Medline

Sacco RL, DeRosa JT, Haley EC Jr, Levin B, Ordronneau P, Phillips SJ, Rundek T, Snipes RG, Thompson JL (2001) Glycine antagonist in neuroprotection for patients with acute stroke: GAIN Americas: a randomized controlled trial. JAMA 285:1719-1728. CrossRef Medline

Shibata M, Ohtani R, Ihara M, Tomimoto H (2004) White matter lesions and glial activation in a novel mouse model of chronic cerebral hypoperfusion. Stroke 35:2598-2603. CrossRef Medline
Shibata M, Yamasaki N, Miyakawa T, Kalaria RN, Fujita Y, Ohtani R, Ihara M, Takahashi R, Tomimoto H (2007) Selective impairment of working memory in a mouse model of chronic cerebral hypoperfusion. Stroke 38:2826-2832. CrossRef Medline

Tanaka Y, Imai H, Konno K, Miyagishima T, Kubota C, Puentes S, Aoki T, Hata H, Takata K, Yoshimoto Y, Saito N (2008) Experimental model of lacunar infarction in the gyrencephalic brain of the miniature pig: neurological assessment and histological, immunohistochemical, and physiological evaluation of dynamic corticospinal tract deformation. Stroke 39: 205-212. CrossRef Medline

Udaka F, Sawada H, Kameyama M (2002) White matter lesions and dementia: MRI-pathological correlation. Ann NY Acad Sci 977:411-415. CrossRef Medline

Uesugi M, Kasuya Y, Hama H, Yamamoto M, Hayashi K, Masaki T, Goto K (1996) Endogenous endothelin-1 initiates astrocytic growth after spinal cord injury. Brain Res 728:255-259. CrossRef Medline

Uesugi M, Kasuya Y, Hayashi K, Goto K (1998) SB209670, a potent endothelin receptor antagonist, prevents or delays axonal degeneration after spinal cord injury. Brain Res 786:235-239. CrossRef Medline

Wakita H, Tomimoto H, Akiguchi I, Kimura J (1994) Glial activation and white matter changes in the rat brain induced by chronic cerebral hypoperfusion: an immunohistochemical study. Acta Neuropathol 87:484492. CrossRef Medline

Wakita H, Tomimoto H, Akiguchi I, Kimura J (1995) Protective effect of cyclosporin A on white matter changes in the rat brain after chronic cerebral hypoperfusion. Stroke 26:1415-1422. CrossRef Medline

Washida K, Ihara M, Nishio K, Fujita Y, Maki T, Yamada M, Takahashi J, Wu X, Kihara T, Ito H, Tomimoto H, Takahashi R (2010) Nonhypotensive dose of telmisartan attenuates cognitive impairment partially due to peroxisome proliferator-activated receptor-gamma activation in mice with chronic cerebral hypoperfusion. Stroke 41:1798-1806. CrossRef Medline 